\title{
Screening for Developmental Delay in the Setting of an Ambulatory Pediatric Clinic
}

\author{
Dawid Rydz \\ Department of Neurology and Neurosurgery \\ McGill University, Montreal \\ May 2006
}

A thesis submitted to the Faculty of Graduate Studies and Research in partial fulfillment of the requirements of the degree of Master of Science in Neurological Sciences.

(C) Dawid Rydz, 2006 


$\begin{array}{ll}\begin{array}{l}\text { Library and } \\ \text { Archives Canada }\end{array} & \begin{array}{l}\text { Bibliothèque et } \\ \text { Archives Canada }\end{array} \\ \begin{array}{l}\text { Published Heritage } \\ \text { Branch }\end{array} & \begin{array}{l}\text { Direction du } \\ \text { Patrimoine de l'édition }\end{array} \\ \begin{array}{l}\text { 395 Wellington Street } \\ \text { Ottawa ON K1A 0N4 } \\ \text { Canada }\end{array} & \begin{array}{l}\text { 395, rue Wellington } \\ \text { Ottawa ON K1A 0N4 } \\ \text { Canada }\end{array}\end{array}$

Your file Votre référence ISBN: 978-0-494-24788-4 Ourfile Notre référence ISBN: 978-0-494-24788-4

NOTICE:

The author has granted a nonexclusive license allowing Library and Archives Canada to reproduce, publish, archive, preserve, conserve, communicate to the public by telecommunication or on the Internet, loan, distribute and sell theses worldwide, for commercial or noncommercial purposes, in microform, paper, electronic and/or any other formats.

The author retains copyright ownership and moral rights in this thesis. Neither the thesis nor substantial extracts from it may be printed or otherwise reproduced without the author's permission.
AVIS:

L'auteur a accordé une licence non exclusive permettant à la Bibliothèque et Archives Canada de reproduire, publier, archiver, sauvegarder, conserver, transmettre au public par télécommunication ou par l'Internet, prêter, distribuer et vendre des thèses partout dans le monde, à des fins commerciales ou autres, sur support microforme, papier, électronique et/ou autres formats.

L'auteur conserve la propriété du droit d'auteur et des droits moraux qui protège cette thèse. $\mathrm{Ni}$ la thèse ni des extraits substantiels de celle-ci ne doivent être imprimés ou autrement reproduits sans son autorisation.
In compliance with the Canadian

Privacy Act some supporting forms may have been removed from this thesis.

While these forms may be included in the document page count, their removal does not represent any loss of content from the thesis.
Conformément à la loi canadienne sur la protection de la vie privée, quelques formulaires secondaires ont été enlevés de cette thèse.

Bien que ces formulaires aient inclus dans la pagination, il n'y aura aucun contenu manquant. 


\section{Table of Contents:}

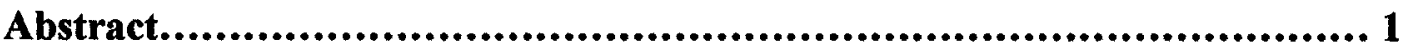

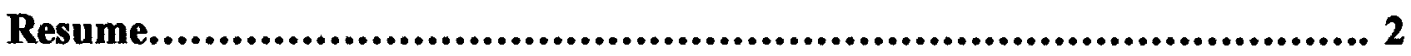

Acknowledgements..................................................................... 3

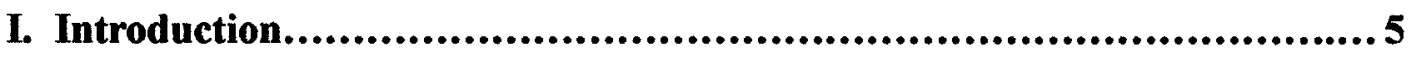

I.1 Childhood Developmental Delay ................................ 5

I.2 Developmental Surveillance.................................... 8

I.3 Developmental Screening ...................................... 10

II. Background information and Rationale ....................................... 16

III. Objectives and Hypothesis ..................................................... 19

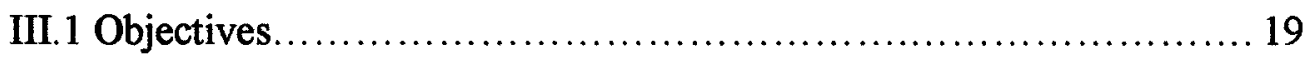

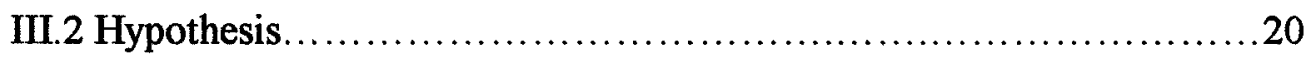

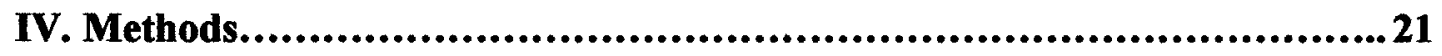

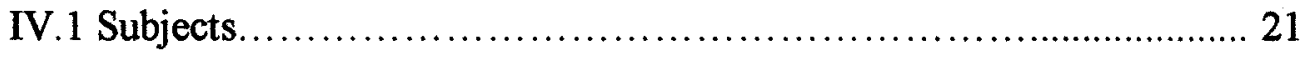

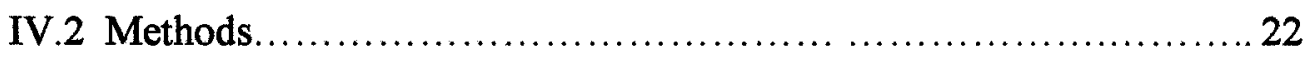

IV.3 Psychometric Measures................................................ 25

IV.3A Battelle Developmental Inventory ............................ 25

IV.3B Ages and Stages Questionnaire ............................... 27

IV.3C Child Development Inventory ............................... 30

V. Results......................................................................... 31

V.1 Descriptive Data ............................................. 31

V.2 Performance on Screening Tools............................ 32

V.3 Ease of questionnaire completion.............................. 34 
V.4 Psychometric Values.

V.4A Psychometric values of the screening questionnaires.......... 34

V.4B Psychometric values after incorporating pediatrician's........ 35 opinion with the parent-completed questionnaire

VI. Discussion..................................................................37

VI.1 Properties of Screening Tests............................... 37

VI.2 Interpretation of Results................................... 40

VI.3 Future Screening Procedures................................. 45

VI.4 Study Limitations............................................ 47

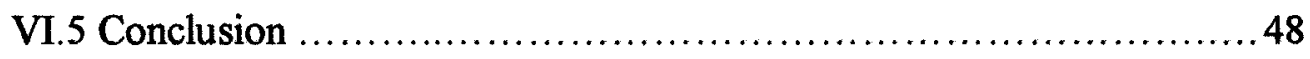

Tables and Figures................................................................ 52

Table 1: Classification of Developmental Delay...................... 52

Table 2: Literature Summary...................................53

Table 3: Demographic Data. .......................................... 54

Table 4: Data concerning child characteristics ...................... 55

Table 5: Performance on test domains within (ASQ or CDI) vs. BDI....... 56

Table 6: Performance on questionnaire- ASQ and CDI.............. 57

Table 7: Psychometric values of screening measures vs. BDI........... 58

Table 8: Psychometric values of ped.'s opinion with screening measures... 59

Figure 1: Flow chart for procedure.................................6 60

Reference List............................................................ 61

Appendix.......................................................................... 69

Appendix 1: Cover letter......................................... 69

Appendix 2: Demographic questionnaire........................... 70 
Appendix 3: Pediatrician's questionnaire .......................... 71

Appendix 4: Consent form..................................... 72

Appendix 5: Questionnaire for parents' opinion of screening instrument....73

Appendix 6: Research Compliance Certificate ........................ 74

Appendix 7: Battelle Development Inventory (first page only) $\ldots \ldots \ldots \ldots 75$

Appendix 8: Ages and Stages Questionnaire (first page only)............76

Appendix 9: Child Development Inventory (first page only) ............ 77

Appendix 10: Waiver from BC Decker INC Publisher.................... 78 


\section{Abstract}

Developmental screening tests greatly improve the accuracy of identifying children with developmental delay. We prospectively tested whether parent-completed questionnaires can be effectively used in the setting of a busy ambulatory pediatric clinic to accurately screen for developmental impairments. We also assessed not only the accuracy of two screening instruments (Ages and Stages Questionnaire (ASQ) and the Child Development Inventory (CDI)) but also whether the pediatrician's opinion regarding the child's development could be used as a potential modifier to improve accuracy. The goal would be to devise a screening paradigm that is both time-efficient and practical.

Three important conclusions were reached: 1) parent-completed questionnaires can be feasibly utilized in the setting of a pediatric clinic; 2) pediatrician's opinion had little effect in ameliorating the accuracy of either questionnaire; and 3) accuracy of these screening instruments did not meet the requisite standard for development screening tests as set by current recommendations. Based on these results and those of other studies, we question whether a single screening instrument at one point in time is sufficient to accurately estimate the developmental status of a child. This study raises important questions about how developmental screening can be performed and suggests that screening should occur over time. 


\section{Resumé}

Les tests de dépistage pour le développement améliorent grandement les chances d'identifier correctement les enfants avec un retard de développement. Nous avons par la suite testé pour savoir si les questionnaires complétés par les parents peuvent être utilisés efficacement pour l'installation d'une clinique pédiatrique ambulatoire occupée à dépister de façon précise les déficiences en développement. Nous avons aussi évalué non seulement la précision de deux instruments de dépistage ('Ages and Stages Questionnaire' (ASQ) et 'Child Development Inventory' (CDI)), mais aussi si l'opinion du pédiatre concernant le développement de l'enfant pourrait être utilisée en tant que modificateur potentiel pour améliorer la précision. L'objectif serait de concevoir un paradigme de dépistage qui soit efficace dans le temps et pratique.

Trois conclusions importantes ont été obtenues: 1) les questionnaires remplis par les parents peuvent être utilisés de manière faisable pour l'installation d'une clinique de pédiatrie; 2) l'opinion du pédiatre a eu peu d'effets pour améliorer la précision des deux questions; 3) la précision de ces instruments de dépistage n'a pas rencontré le standard requis pour les tests de dépistage en développement tels qu'il est décrit par les recommandations actuelles. Sur la base de ces résultats et ceux d'autres études, nous nous questionnons à savoir si un seul instrument de dépistage à un moment donné dans le temps est suffisant pour estimer de façon précise le statut de développement d'un enfant. Cette étude soulève des questions importantes sur la façon dont le dépistage en développement peut être fait et suggère que le dépistage devrait être fait sur une période étendue. 


\section{Acknowledgments}

Note: This thesis contains excerpts from a published review article entitled'Rydz D, Shevell MI, Majnemer A, Oskoui M: Developmental Screening. $J$ Child Neurology 2005;20:4-21.' This paper was written by the first author, Dawid Rydz, under the guidance of the second author Shevell MI. Shevell MI, Majnemer A and Oskoui M contributed to editing. (see Appendix 10)

Foremost, I would like to thank my supervisor Dr. Michael I. Shevell for giving me the opportunity to join his team on the fifth floor. By trusting me, he

gave me the independence during this project to grasp the intricacies of conducting clinical research. Thank you for your patience and endless support over the last two years.

I am indebted to my Advisory Committee members, Dr. Bernard Rosenblatt, MD, and especially Dr. Annette Majnemer, Ph.D., who shared with me her expertise in statistical analysis and interpretation.

Three other people played a vital role and whose participation was a requisite for the completion of this project. I would like to thank Myriam Oskoui, MDCM, who devised the initial objectives for this study. Also, I would like to thank Nancy Marget, MA, and Myriam Srour, MDCM, for not only playing a great role in data collection but also for their advice and warm smiles.

Rena Birnbaum was instrumental not only in the capacity of the occupational therapist who performed all the developmental assessments but also as an advisor. 
I am indebted to all the aforementioned people for their friendship and their kindness and in this group I must include Nicholas Hall.

The staff at the Children Care Clinic have aided in coordinating the study between offices especially Dr Mitchell Shiller and Cathy Ammendolea.

Finally, I would also like to thank the Montreal's Children Hospital and Child Neurology Foundation for their generous funding. 


\section{Introduction}

\section{I.1 Childhood Developmental Delav}

Developmental delay can be restricted to one stream of development or to two or more streams of development (global developmental delay). ${ }^{1-6}$ The domains of development can be conceptually categorized into four major areas:

1) Motor $^{7,8}$ development encompasses both gross motor ability (the control of large groups of muscles involved in walking, sitting or transferring from one position to another) and fine motor abilities (the manipulation of objects with the hands in order to eat, draw, play etc). Children progress through motor milestones in an orderly fashion, attaining these functions in a clear and sequential process. Motor delay is defined as a significant delay in motor abilities without delay in other developmental categories.

2) Language $^{7,8}$ performance consisting of articulation, receptive and expressive language skills, and the utilization of non-verbal symbols encompasses a major stream of development, arising from the interaction between innate communication abilities and environmental influences. Any significant delay in language or speech skills without delay in other developmental domains is categorized as a developmental language disorder, developmental dysphasia, or specific language impairment.

3) Adaptive/cognitive $^{7,8}$ development is a measure of the child's ability at problem solving through intuition, perception, verbal and non-verbal reasoning. 
Moreover, it encompasses the ability not only to learn and understand but also to retain this information and apply it as needed.

4) Personal/social ${ }^{7,8}$ domains encompass the child's interactions as shown by the formation and maintenance of relationships and responsiveness to the presence of others. Psychosocial delay presents itself over time as behavioral abnormalities that differ from normal behavioral responses by their quantity, severity, nature and duration. Personal development involves the formation of self-help skills in various activities of daily living such as feeding, dressing and toileting. $^{7,8}$

Generally, developmental delay is a term used to describe a child who does not reach developmental milestones at the expected age even after allowing for the broad variation of normality. A classification scheme for neurodevelopmental disabilities is provided in Table $1 .^{9}$

An estimated $5-10 \%$ of the pediatric population has a developmental disability. ${ }^{10}$ There has been increasing pressure to identify these children at an earlier age with the current focus being on infants (birth to two years of age). ${ }^{11}$ This has been spurred by several factors. Firstly, the neuromaturational view that development is intrinsically pre-programmed and takes place in a predictable sequence that is essentially hardwired into the central nervous system (CNS) and unchangeable by environment, has become less influential. ${ }^{12}$ Alternatively, the systems approach views the child's development as dependent on environmental influences, suggesting that a favorable environment could enhance and optimize development. ${ }^{12}$ It is the systems approach theory that 
now governs the manner in which neuro-development is viewed. Secondly, early intervention programs not only are beneficial in maximizing developmental attainment but also provide potential cost-benefits to society. For example, the Perry School Study, examining the merits of intervention, estimated that two years in an early intervention program (at age 3 and 4) could save society up to $\$ 100,000$ per child. ${ }^{13}$ The costs (most influenced by the duration, intensity, number of services and reliance on the parents to partially bear the cost) appear to be far less than the economic benefits that society bears as a result of the consequences of untreated developmental delay. ${ }^{13}$ Furthermore, the effects of intervention remain apparent into adulthood and create important differences with those children who did not receive intervention. ${ }^{13}$ As such, federal law PL-99142 (The Education of the Handicapped Act Amendments) enacted in 1986 in the United States of America, calls for appropriate education for all children with disabilities as well as an active participation of state education agencies in the identification and evaluation of these children. ${ }^{14}$ It is believed that beneficial gains will be greatest if the child participates in intervention services as early as possible, a concept iterated in public laws such as the Individuals with Disabilities Education Act Amendments (IDEA) of 1997 which mandates early identification and intervention for children with developmental disabilities. ${ }^{12,15}$ Finally, professional organizations such as the American Academy of Pediatrics strongly endorse the early identification of delayed children by health practitioners. ${ }^{12,16}$ 


\section{I.2 Developmental Surveillance}

The strategy used by primary care providers to monitor a child's progress is termed developmental surveillance. Developmental surveillance is an ongoing process of monitoring the status of a child by gathering information about the child's development and behavior from multiple sources, including direct observation of the child's behavior and elicitation of concerns from parents and relevant professionals. ${ }^{17}$ Moreover, the pediatrician will often take a relevant developmental history and complete an age appropriate checklist to record developmental milestones. In successful surveillance, development is viewed in the context of the child's overall health and well-being and not isolated from other domains pertaining to the child's health. ${ }^{18}$ In this paradigm, developmental screening can be also included.

Both the American Academy of Pediatrics and the British Joint Working Party on Child Health Services recommend developmental surveillance as an effective means to identify children with delay. ${ }^{19}$ Furthermore, eliciting the caregiver's concerns encourages the caregiver's ongoing participation in their child's welfare. This simultaneously allows the pediatrician to assess the parent's knowledge and attitude about their child's development and is an opportune time to exchange information while offering anticipatory guidance. ${ }^{17,20}$ Consequently, developmental surveillance can improve the physician-parent relationship lending itself to a more cooperative situation if developmental problems should indeed arise. ${ }^{17}$ 
Even though developmental surveillance is the tool utilized by the majority of physicians, research has shown that subjective clinical impressions alone are not effective in solely assessing development. For example, in Great Britain only $45-55 \%$ of children with developmental disabilities are detected before school entrance. ${ }^{21}$ Moreover, utilizing clinical judgment alone detects fewer than $30 \%$ of children who have mental retardation, language impairments or other developmental problems. ${ }^{22}$ Behavior problems are also under-identified as one study demonstrated that only 1 out of 6 children with severe behavioral problems was identified when the pediatrician used developmental surveillance alone. ${ }^{23}$

Though developmental surveillance can be a powerful identification tool, fully implementing this strategy in the context of medical practice is difficult for several reasons. First, and perhaps most importantly, time constraints often do not allow the practitioner to implement comprehensive surveillance and it may be omitted altogether when dealing with more pressing health problems that initially prompted the visit. In clinics where visits have been trimmed to an average duration of 12 minutes, the primary care practitioner will simply not have enough time to perform all the necessary steps for comprehensive developmental surveillance. ${ }^{21,24}$ Secondly, because success in developmental surveillance is dependent on a continuous and ongoing process, it is not likely to work well for those infants receiving periodic, infrequent care by different health providers. ${ }^{25}$ Finally, the effectiveness of this strategy is dependent on the practitioner's knowledge and experience. Inadequate training 
regarding developmental issues compromises the practitioner's skills in early identification ${ }^{26}$. For instance, failing to properly elicit parental concerns can be a significant factor leading to missed early identification. ${ }^{23,27}$

\section{I.3 Developmental Screening}

An adjunct to developmental surveillance is developmental screening. Generally, screening refers to the process of systematically testing whole populations of children to identify those at high risk for clinically significant, but as yet, unsuspected deviations from normality. Standardized screening tests help remind practitioners to dedicate time to developmental assessment and also provide a standardized structured format to assist clinicians in making skilled observations. ${ }^{12,28}$ Most importantly, developmental screening improves the accuracy with which children are identified when compared to decisions based only on clinical judgment. ${ }^{20,23,29}$ Also several professional organizations, including the American Academy of Pediatrics, have recommended that "all infants and children should be screened for developmental delay". ${ }^{11}$ Consequently, screening tests are seen as advantageous instruments to identify developmental impairment.

Even though there has been a growing propensity for practitioners to be more attentive to developmental delay and to use standardized screening instruments ${ }^{30}$, there still remains a disparity between what is advocated and what is practiced. A recent study showed that only approximately $20 \%$ of primary care clinicians used a standardized tool when a psychosocial problem was 
recognized. Similarly, only $23 \%$ of primary-care physicians polled used a standardized instrument regularly. ${ }^{31,32}$ The results of this survey are intriguing considering that previous studies have documented significant weaknesses in relying solely on developmental surveillance.

There are several reasons why pediatricians fail to use developmental screening even when they have been encouraged to do so by responsible professional societies and when doing so can greatly improve the accuracy of identifying delayed children. ${ }^{33}$ In a survey performed by the American Academy of Pediatrics, the most prominent deterrent, voiced by a majority $(82 \%)$ of primary care practitioners, is time constraint. ${ }^{34}$ Administering and scoring screening tests in a standardized fashion could take from 15 to 40 minutes: such time is not readily available in the context of a busy pediatric medical practice. The lack of medical staff (48\%), and the burden of costs (44\%) in monitoring developmental delay for which they are not well compensated were also listed as significant factors. ${ }^{34}$ An additional deterrent to physicians is the vast selection of screening measures. Screening tests are not regulated by any professional society and there is little guidance given to the practitioner in choosing accurate and appropriate tests. ${ }^{21}$ Screening results also vary depending on whether the child is compliant, tired, or disoriented by a foreign environment. Consequently, multiple tests, repeated over time, may be needed to gain a good indication of the actual nature of the child's current development. ${ }^{11}$ For these reasons, physician-administered tests may not be feasible as the primary source for identifying developmentally delayed children. 
Alternatively, developmental screening tests can also be based on the caregiver's experiences with the child. Parent-completed screening questionnaires have been gaining more support as measures that are just as accurate as those performed by the pediatrician. Current research strongly supports the observation that parents, regardless of differences in socioeconomic status, geographical location or parental well-being can give accurate information about their child's development. ${ }^{27,35-41}$ When systematically asked questions on development in a structured format, a parent's concern about development has been revealed to be highly accurate. ${ }^{36}$ These concerns have been methodically examined for their ability to correctly identify developmental problems. ${ }^{36}$ For example, parental concerns about speech and language, fine motor or global functioning accurately predicted developmental problems with a sensitivity approaching that of physician-completed screening tests. ${ }^{37}$ Other parental worries such as those involving daily-living skills, social or gross motor functioning were less sensitive indicators of possible developmental problems. ${ }^{37}$ Even those children who had concerned parents, but who did not qualify for special educational programs, received "substantially lower scores on socialization, fine motor, gross motor, expressive and receptive language subtests of the Child Development Inventory". ${ }^{42}$ Hence, these parents were not falsely concerned, but presumably highly observant of even small deviations from established norms in these domains. This further supports the parents' ability to accurately describe and report their child's development. ${ }^{42}$ 
The reliability and the validity of parent-filled questionnaires have also been assessed. Test-retest reliability showed high correlation coefficients ranging from $0.80-0.99$ when the tests were completed one week apart. ${ }^{23}$ Reliability is highest when the questionnaires are presented in a well-structured manner, with specific, detailed and well-worded questions. ${ }^{40}$ Moreover, despite differences in physician's and parents' views of developmental skills, agreement between the two is still high with a congruence ranging from 75 to $90 \%{ }^{43-45}$

Parent-completed measures have additional advantages. A study showed that almost $70 \%$ of mothers were more worried about their child's behavior or development than medical issues, but only slightly more than a quarter $(28 \%)$ actually discussed these concerns with their pediatrician. ${ }^{46} \mathrm{~A}$ parent-filled questionnaire can immediately bring these concerns to light prompting extended discussion with a health practitioner. Moreover, the involvement of parents immediately from the onset of the identification process will encourage a more pro-active outlook towards their child's development. ${ }^{13}$ This is also advantageous because parents will have a more thorough and detailed understanding of their child's capabilities and skills. In the unfamiliar environment of the physician's office, the infant may be nervous, uncooperative or distracted and hence may not perform well on physician-administered screening tests. ${ }^{22}$ On the other hand, observant parents comparing their child's skills with those of others have a better and more intimate knowledge of their child's actual capabilities. For example when assessing language skills, parents observe the child continually in a familiar home environment and may witness a 
more representative and extensive language repertoire than that demonstrated during a brief interval in the physician's office. For short-term costs, parentreport screening tests are cost-effective. A study evaluating the total cost of screening, taking into account both administration costs and consultation costs, estimated the costs of parent-report measures to vary between $\$ 11$ to $\$ 17$ per test administered, while those screening tests administered by a health professional ranged from $\$ 22$ to $\$ 82 .{ }^{47}$ Finally, parent-completed questionnaires not only can be administered routinely every several months, but also can be administered in various settings. For instance, they can be completed over the phone, during an interview, filled out manually in the waiting room, or mailed to the subject's home. Even computer web-based administration or the use of a personal digital assistant (PDA) is conceivable.

Parent-report screening tests have few disadvantages except for problems that might arise due to illiteracy. Parents with limited literacy may respond randomly to questionnaires or omit items. ${ }^{22}$ This, however, is easily avoided by simply asking whether the parent would like assistance in filling out the questionnaire or by performing the screen through an oral interview. Consequently, utilizing parent-completed questionnaires for developmental screening appears to be a strategy with important advantages over other screening methods. Indeed, Regalado in his 2001 review advocates: "The available evidence suggests that assessment of developmental issues might benefit from the wider use of structured, validated approaches. ...systemic assessment of parent's concerns can play a role in identifying children with 
developmental problems, replacing or supplementing longer and more costly developmental screening assessments..." (page 1318) ${ }^{48}$. 


\section{Background information and Rationale}

The literature concerning the topic of developmental screening with parent-completed questionnaires has several shortfalls, which limits the applicability of their results to the setting of a pediatric clinic. (See Table 2 for a summary of the studies available that have utilized the Ages and Stages Questionnaire (ASQ) and the Child Development Inventory (CDI)) ${ }^{20,49-52}$ Firstly, previous studies have focused on specific cohorts that have been already flagged as being delayed or consisted of high-risk infants (i.e. very low birth weight and prematurity). ${ }^{49,51,52}$ Secondly, sample sizes in the majority of studies, which rely on specific cohorts, are small and the applicability of these results to the general population as a whole is uncertain. ${ }^{49,51,52}$ Thirdly, screening was performed on children older than two years of age in some studies. ${ }^{51,52}$ This represents an unfavorable situation as earlier identification and intervention predisposes the child to a much more favorable outcome such that ideally identification should take place before the second year of age. ${ }^{11}$ Other studies, using screening instruments as the gold standard, must also be analyzed skeptically, as validating a screening instrument with another parent-completed screening instrument can produce inaccurate results. ${ }^{51}$ Finally, these studies do not offer guidelines that primary-care practitioners can use to effectively screen for developmental delays. ${ }^{20,49-52}$ Part of the reason might be that these tests are not designed with an emphasis on keeping the methods in line with the actual reality of the clinical setting. To illustrate this point, studies have been conducted outside of the pediatric clinic or with the help of non-office members 
such as a graduate student. ${ }^{20,52}$ Indeed, the majority of research has focused on validation or predictive value and not on actual methods or practicality. In his review of the literature Sonnander states: "few... studies focusing on evaluation of developmental screening programs conducted within a clinical setting were found" whereas "empirical research into child development and the predictive value of developmental tests is extensive" (page 20). ${ }^{53}$ Thus, there is a lack of pragmatic research addressing the area of how a primary care practitioner should screen for developmental delay in a community.

The need to find a practical method to screen for developmental delay has been indicated in the literature as early as 1979 . Shonkoff in 1979 concluded that: “...more precise techniques for pediatric developmental assessment and conclusive evaluations of specific interventions will have to be produced.... The current difficulty in defining criteria for optimal pediatric management emphasizes the need for creative, methodologically sophisticated research in the area... (page 512)". ${ }^{54}$ Furthermore, Sices states: “The AAP... does not provide specific guidance on how a primary-care physician is to perform developmental surveillance and screening. Research on how these guidelines can be best implemented in the context of primary-care practice would help standardize and enhance the value of the experience for patients and families" (page 415). ${ }^{33}$ Clearly, there is a need for the formulation of guidelines that can be used by primary-care practitioners in a time and cost efficient manner.

Consequently, this study was devised to provide a more thorough and objective analysis of what is needed to improve present screening methods. 
Creating an efficient system for recognition of developmental problems would mean earlier referral to specialty diagnostic and therapeutic services and hopefully a better prognosis and eventual outcome for a delayed child. Presently, there is little research aimed at linking the use of these parent-filled questionnaires with an efficient, feasible and comprehensive program to screen for children with developmental delay. The important questions to ask are: 1) Can these tests be completed by the caregiver in the waiting room of a busy pediatric clinic? 2) What role can the practitioner play in ameliorating the questionnaire's accuracy? 3) How accurate are these parent-completed questionnaires when utilized in such a setting? Ideally, the questionnaires and the relevant issues must be focused to identify delayed infants before two years of age. These aspects of parent-completed screening tests need to be examined systematically to provide the rational foundation for a more feasible, clear and accurate screening agenda. 


\section{Objectives and Hypothesis}

\section{III.1 Objectives}

In the context of the busy pediatric clinic, the practitioner faces many obstacles that discourage the effective use of both developmental surveillance and practitioner-completed developmental screening tests. Emerging as an accurate and time-efficient alternative is the parent-completed questionnaire. This study was implemented to determine how effective parent-filled developmental questionnaires are as an accurate and feasible tool to identify delayed children during a clinical visit. To ensure this, three objectives were set. 1) This study will assess the practicality of using parent-report instruments in the waiting room of a busy pediatric clinic to ascertain whether the parent has enough time to complete the screening questionnaire. The feasibility of completing these questionnaires in the busy environment of the clinic constitutes a critical feature of a successful screening procedure. 2) The results of each screening instrument will be incorporated with the physician's overall intuitive opinion of the child's development to assess if the combined result can act as a potential modifier to capturing developmentally impaired children. 3) Finally, this study will examine the accuracy of two parent-completed tests [Ages and Stages Questionnaire (ASQ), and the Child Developmental Inventory (CDI)] taking into account their respective predictive values, sensitivity and specificity. 


\section{III.2 Hypotheses}

A. Feasibility of procedures:

1) $>90 \%$ of parents will complete the developmental screening forms appropriately while waiting in the pediatrician's waiting room.

B. Pediatrician as a potential modifier

1) Incorporating the pediatrician's possible concerns will ameliorate the psychometric values of the screening tests.

C. Estimates of accuracy

1) Both screening tools (ASQ,CDI) will have similar percentages (total proportions of wrong labels) of false positive and negative results.

2) Based on previous data, both screening tests utilized will produce sensitivity and specificity values above 0.70 . 


\section{Methods}

\section{IV.1 Subjects}

Subjects were recruited from the patient population of the Children's Care Clinic (CCC). Located in Pierrefonds (Quebec) the CCC is an exclusively pediatrics-group practice, incorporating seven full-time pediatricians. It is community-based, drawing from the suburban, largely middle class population of Pierrefonds, Dollard Des Ormeaux, Ile Bizard and Kirkland, providing comprehensive primary pediatric care to its clientele. Its patient demographic and appointment systems are fully computerized.

Subjects were recruited at the time of their 18-month old visit. This is a standard routine pediatric office visit coinciding with the administration of a number of vaccines. The 18-month timing was also chosen as it allows for accurate assessment of motor, language, social and cognitive skills by standardized developmental screening instruments. Furthermore, successful identification of delays at this point in time would represent a substantial improvement over what is currently achieved (i.e. typically referrals occur at 2-3 years of age or older $)^{39}$. All subjects turning 18 months were contacted and eligible to participate unless there was an established significant developmental disability. Recruitment was terminated after 101 assessments were completed with the Battelle Development Inventory (BDI) (Only 101 BDIs were completed due to funding limitations). Parents completing the questionnaire required a reading knowledge of English, as the questionnaires are presently available only in English. 


\section{IV.2 Methods}

The database at the CCC was continually scanned for subjects who were turning 18 months of age in the forthcoming two months. The caregivers were sent a cover letter describing the study and signed by the pediatricians at the CCC indicating their support (See Appendix 1). A phone call made to the family was timed soon after the receipt of the letter at which time any questions or concerns regarding the study were addressed and verbal consent or refusal was noted.

If a parent refused participation, the reason for refusal was obtained and noted. All parents who refused were also asked to complete a simple demographic questionnaire over the phone that gathered basic demographic information on employment, income and education (See Appendix 2).

If verbal consent was given, the subject's appointment date was noted and a dossier was placed in the child's folder at the clinic. A week prior to their appointment, the subjects were also given a phone call reminder of their participation in this study. Each dossier contained: 1) one of two pre-selected parental-report measures, Ages \& Stages Questionnaire (ASQ) or Child Development Inventory (CDI), depending on group assignment which was done using random number table and blocking to ensure equal distributions. These two measures were selected because both are well standardized and validated and have been used in studies reported in the literature (See section entitled "Measures"). 2) The parents were also asked the following question: Do you have any present developmental concerns that warrant further investigations 
(Yes/No)? If answered "yes", the caregiver chose from a checklist if this concern related to motor (gross and/or fine), language, social or cognitive domains or to more than one domain. A space was also provided for any comments (See Appendix 3). 3) A simple demographic questionnaire was placed in the dossier in order to obtain information on the parents' level of education, employment and combined income (See Appendix 2). 4) A consent form for participation was also included (See Appendix 4). 5) Finally parents were asked a simple Likert-type questionnaire regarding their impression of the questionnaire they had completed (See Appendix 5).

Completed questionnaires were scored according to established procedures for each measure. The number of incorrectly completed questionnaires for each measure was noted. Those children who failed the parent-filled questionnaire underwent the Battelle Developmental Inventory [BDI] (the "gold standard" for the purpose of this study), which was administered approximately three months after the initial screen by an experienced pediatric occupational therapist who was blinded to both the screening instrument used and the results obtained (See 'Measures' for Description of the BDI). ${ }^{40}$ The three month wait instituted in this study represents the three month referral wait typically experienced by families awaiting a more thorough developmental assessment; and at 21 months, the infant falls in the middle of the 18-23 month marking scheme of the BDI giving the most accurate estimation of the infant's real abilities. 
To yield false negative estimates, an equal number of children scoring within the norms of the screening measures also underwent BDI testing (Figure 1 for flow chart of procedure). Controls were the next same gender child participating in the study who had scored normally. In this fashion, the control group was selected in an unbiased manner. Because of constraints posed by funding and time available from the occupational therapist, only 101 children underwent the BDI after which ongoing study recruitment was terminated. Though this is not as favorable as testing all the participants with the BDI, 101 BDIs represents a large enough sample to be a good indicator of the accuracy of the ASQ and CDI.

Note: Control subjects for this study were the next same gender child participating in the study who had scored normally. Because no criteria was set to ensure that the failed subject was paired with a control who had also performed the same screening questionnaire, the number of controls for each screening test does not equate with the number of failed scores for that particular questionnaire. Specifically, there are 24 controls for 41 ASQ failed scores while there are $\mathbf{2 8}$ controls for $8 \mathrm{CDI}$ failed scores.

The pediatrician providing care to the child was blinded to the actual questionnaire used and the results obtained, but was asked as part of the study to answer a question identical to the one given to the parent regarding any possible concerns about the child's development (See Appendix 3). This question was answered at the time of the subject's visit by simply ticking off the appropriate response box(es). The results of this simple questionnaire were used to establish 
what role the pediatrician could play in influencing the accuracy of the chosen questionnaires in identifying children with suspected developmental impairment. (Therefore, only the data collected for the children also assessed with the BDI was utilized.)

Parents who had agreed over the phone to participate but who did not return the questionnaire were contacted by phone and reminded to return the questionnaire. If the questionnaire was not returned three months after it was due, the parents were sent a demographic questionnaire to assess whether any parameters differentiated these parents from those that actually completed the questionnaire. Families with whom we had no personal contact by phone were not included in the study.

Throughout this study, data obtained was stored and managed on secure computers within the MCH Division of Pediatric Neurology with separation of subject identifier variables. Ethical approval for conduct of the study was obtained from the Research Ethics Board of the MCH-MUHC (See Appendix 6 for Research Compliance Certificate). Data storage and analysis was performed using SPSS 12.0 and all data entered was verified for errors.

\section{IV.3 Psychometric Measures}

\section{IV.3A Battelle Developmental Inventory}

The Battelle Developmental Inventory ${ }^{55}$, a psychometrically sound developmental assessment for children from birth to 8 years, is widely used in studies evaluating developmental delay and in U.S.-mandated early intervention 
programs. The BDI gathers information via a structured test format, interviews with the caregiver and direct observation of the child. Items are assigned an age level at which $75 \%$ of the norming population was able to perform. It is composed of 341 items that evaluate five domains: personal/social, adaptive, motor, communication and cognitive with each domain further subdivided into subdomains. Items are scored as "typically" signifying fully developed skills; "sometimes" signifying emerging abilities; or "rarely" signifying absent skills and are scored 2,1 or 0 respectively (See Appendix 7). The total score in any domain that is 1.5 standard deviations or less below the normal mean is interpreted as a failed test. The authors recommend the test for many functions including general screening, assessment of children that have previously been flagged as having developmental delay or in identifying strengths and weaknesses of normal or developmentally impaired children. The manual states that the assessment can be completed in an hour or less, but that it may take up to two hours with children under three years of age. The tester of this assessment should be familiar with the items before administration.

The norming sample for the BDI was chosen from 28 sites found in 28 states and was stratified by regions and sub-regions, race and gender. Test-retest reliability is high for all ages fluctuating from $0.94-0.99 .{ }^{55}$ Both content and construct validity were ensured. For criterion-related validity the test was compared with various measures and showed strong correlation with the Vineland Social Maturity Scale, Developmental Activities Screening Instrument and the Stanford-Binet Intelligence Scale. 


\section{IV.3B Ages and Stages Questionnaire}

The Ages and Stages Questionnaires ${ }^{56}$ are 19 parent-report questionnaires that span the age range between 4 to 60 months. Questionnaire points include $4,6,8,10,12,14,16,18,20,22,24,27,30,33,36,42,48,54$ and 60 months of age. (Infants born more than 3 weeks premature are given an adjusted age up to the time they are 24 months old.) Each questionnaire is composed of three sections: a brief set of demographic items, 30 questions on the infant's or child's development assessing 5 domains equally (communication, gross motor, fine motor, problem-solving and personal/social); and seven open-ended questions eliciting parental concerns. The choice of responses for each item is "yes", "sometimes", or "not yet" receiving scores of 10,5 , and 0 respectively (See Appendix 8). The test is graded according to the domain tested and compared to an empirically derived screening cut-off score and takes approximately 10-15 minutes to complete.

The test was standardized on a sample of 2,008 children that were stratified on the basis of age, social economic standing, gender and ethnicity though overall Hispanics were under-represented, Native Americans were over represented. The ability to identify children with delay varied from $51 \%$ (4 months) to $90 \%$ (36 months) depending on the age at the time of assessment with an overall sensitivity of 0.75 , while specificity varied from 0.81 to 0.92 with an overall value of $0.86 .{ }^{41}$ Specifically, the 18 -month ASQ was never standardized but rather it was composed of age-appropriate items from the 16 month and 20 month questionnaire. The manual does not have psychometric 
data for the 18-month test; however, the values for the 16 -month and 20 month questionnaire are: 0.73 and 0.66 for sensitivity respectively and 0.81 and 0.90 for specificity respectively. ${ }^{56}$

Test-retest and interrater reliability were high $(r=.94)$ and concurrent validity ranged from $0.76-0.91$ or 0.88 overall using various standardized assessments (Bayley Scales of Infant Development-II, Gesell Development Schedule, Stanford-Binet Intelligence Scale, McCarthy Scales of Children's Abilities). ${ }^{49}$

Even though the ASQ states that the questionnaire can be used in-clinic, the ASQ is meant for mail-out purposes to be completed at home at the specific age intervals listed above. Because of this, the instructions ask the parents to attempt every activity with their child and if the child is non-compliant, to try at a later time. Unfortunately, this was not feasible in the context of a busy waiting room. Thus, these instructions were removed and parents were asked to base their responses on their intuition and previous experiences. Moreover, these tests are meant for a specific age but the age at which infants have their 18month vaccination shot varies by several weeks. As a result, we used the 18month ASQ for children between the ages of 18 and 20 months. We used the 20-month ASQ for all children between 20-22 months. The ASQ manual does state that completion of the questionnaire in the waiting room is the least accurate method since the parent has limited time to complete the activities, and the appointment might not correspond to the exact age at which the most accurate results are produced. 


\section{IV.3C Child Developmental Inventory}

The Child Developmental Inventory ${ }^{57}$ (a 1992 revision of the Minnesota Child Developmental Inventory) is useful for testing children whose ages range from birth to 6 years. It consists of 300 items: 270 items composed of yes/no answers about the child's development and 30 items evaluating various sensory, physical, motor, language and behavioral problems. These items are grouped into 8 sub-scales: social, self-help, gross motor, fine motor, expressive language, comprehension, letters and numbers. Each scale is scored by tallying the "yes" answers and a child that receives a score that is 1.5 standard deviations below the mean is graded as 'borderline', while a child greater than two standard deviations below the mean is graded as "delayed" (See Appendix 9). The parent needs approximately 15 minutes to complete this screening instrument. ${ }^{20}$

Standardization for the Child Development Inventory consisted of a sample of 568 children reflecting social, economic and racial diversity representing the average performance of a white middle class community. ${ }^{20}$ Recent studies evaluating the usefulness of this test in high-risk populations demonstrated a sensitivity of 0.73 and specificity of 0.87 leading the investigators to conclude that it is "a useful and cost effective screening measure for determining developmental outcome" ${ }^{51}$ Correlations with the Cognitive Adaptive Test/Cognitive Language Auditory Milestone Scales $(r=87)$ and Bayley Scales of Infant Development- ${ }^{\text {nd }}$ ed (r=.86) are high, demonstrating the measure's overall validity. ${ }^{52}$ 
The CDI was reformatted for the purposes of this study. In its original form, the CDI is to be answered on a separate marking sheet similar to a scantron; such that, the questions are found in one booklet and the answers are written in another. To simplify the process for our study's parents, the CDI was retyped and presented in a format where the parent can read the question and immediately answer in the same booklet. An example of how the CDI was presented is given in Appendix 9. 


\section{Results}

\section{V.1 Descriptive Data}

Over the recruitment period we received the names of 532 possible children from the database at the CCC. From this list, 84 children were excluded because a) the children were no longer being followed at the clinic (60 children), b) the subjects had moved (12 children), c) the parents did not speak or read English (8 children), d) the child had an established developmental delay ( 2 children), e) the study terminated before the 18-month appointment had been booked ( 1 child), or, f) the subject had passed away ( 1 child). Of the 448 remaining children, we were unable to contact 92 children; therefore, these were also not included in the study. The remaining 356 children we successfully contacted and of these 317 families (90\%) agreed to participate over the phone while 39 families $(10 \%)$ refused. Finally, of the 317 who had agreed over the phone, 5 returned the screening questionnaire ( 3 ASQs and 2 CDIs) incomplete and 64 did not return the screening questionnaire at all despite regular subsequent prompting. Those that had originally agreed to participate over the phone but never returned the parent-report questionnaire were labeled as 'false participants'.

The total number that completed either the ASQ or CDI questionnaire was 248. Table 3 shows the demographic data of these three groups: true participants, false participants and refusals. It is important to note that this 
community is middle class since the majority have a family income over $\$ 80,000$ (Canadian) and have attended a post secondary institution.

The average age of the children who participated in the study was $18.4 \pm 0.64$ months. The data for gestational ages and gender of the children is summarized in Table 4.

\section{V.2 Performance on the ASO, CDI, BDI and pediatrician's questionnaire}

Of the 134 ASQs that were returned completed, $53(40 \%)$ children failed. (The incidence of developmental delay is approximately $10 \%{ }^{10}$; thus, the ASQ overestimates.) The domain that the infant failed most often on the questionnaire was communication (46) followed by problem solving (7), gross motor (4), social (4), and fine motor (3). Forty-one children of the 53 that failed the screening tool continued study participation and underwent BDI assessment. (i.e. 12 dropped out)

Conversely, of the 114 children that were assessed by the CDI, only 11 failed signifying a failure rate of $9 \%$. Expressive language (5) was again the most likely domain to be failed, followed by gross motor (5), fine motor (1), self-help (1) and language comprehension (1 failure). Of the 11 that failed the CDI, 8 children continued study participation and undertook BDI assessment. (i.e. 3 dropped out)

In total, $101 \mathrm{BDI}$ assessments were performed. Twenty-nine children received a failing score. Similarly, the domain which was failed most often was communication (17) followed by gross motor (11), cognition (6), personal-social 
(3) and adaptive (1). Of the 101 BDIs performed, 49 children were those who had previously failed one of the questionnaires, while 52 infants were control subjects. (The difference in the overall number between children that failed the questionnaire and their overall number of controls lies in the fact that three parents whose child failed the screening tool could not be booked for the BDI assessment and hence lost to follow up). Of the 101 BDIS performed, 41 failed ASQs were assessed with the BDI and 8 failed CDIs were assessed with the BDI while the remainder $52 \mathrm{BDI}$ assessments were performed on control subjects.

Kappa analysis was conducted to evaluate the extent of agreement between the screening tests and the BDI. The agreement between the two questionnaires (ASQ and CDI) and the BDI was poor to fair (.04, 0.36 respectively).

Failures in specific domains of the parent-completed screening tool were compared to the BDI "gold standard". Even though the number of subjects did not allow us to run full statistical analyses several pertinent points can be deduced from the descriptive data summarized in Table 5. The ASQ overidentifies and produces many false positives. This is most obvious for the communication domain in which 35 infants failed with only 10 failures being supported by the BDI results. The ASQ also over-referred unwarranted concerns for the domains of social and problem solving skills. On the other hand, the CDI seems to be a much more accurate questionnaire; for example, in the gross motor domain, the CDI correctly identified all delayed children in this 
domain as confirmed by the BDI. Also, in comparison to the ASQ, it produced relatively fewer false positives.

\section{V.3 Ease of Questionnaire Completion}

Closer examination was given to the rates of completion and to parent's opinion of the questionnaires as to assess feasibility of use. Overall, the CDI was more likely to either be returned late ( $27 \%$ for CDI vs. $22 \%$ for ASQ) and not to be returned at all ( $23 \%$ for CDI vs. $17 \%$ for ASQ). This difference was to be expected as the CDI contains more items to answer and is thus more labor and time intensive. Overall, $81 \%$ of the ASQs were returned completed and $75 \%$ of the CDIs were returned completed.

The Likert-type questionnaire (Appendix 5) was used to assess the parent's opinion of the questionnaires. The options - very easy, easy, neutral, difficult, and very difficult - were given the numerical values 1 through 5 respectively. The ASQ received a mean value of $1.5 \pm 0.6$ while the CDI received a mean value of $1.6 \pm 0.7$. Therefore, the majority of the parents ranked the questionnaires as either very easy or easy with the difference between the ASQ and the CDI being negligible. Table 6 summarizes this data.

\section{V.4 Psvchometric Values}

\section{V.4A Psychometric values of the screening questionnaires}

Using the BDI as the gold standard, we assessed the ASQ and the CDI for their psychometric properties: sensitivity, specificity, positive predictive value 
and negative predictive value. Not one of the questionnaires proved to be an ideal screening instrument. The ASQ had moderate sensitivity $(0.67)$ but poor specificity (0.39). Conversely, the CDI had poor sensitivity (0.50), but excellent specificity (0.86). Table 7 summarizes this psychometric data for the ASQ and CDI.

\section{$V .4 B$ Psychometric values after incorporating pediatrician's opinion with the} parent-completed questionnaires (ASQ and CDI)

Lastly, the physician's opinion was incorporated with the parentcompleted questionnaires to see if this could be used as a potential modifier. As a result, those children a) who had failed the parent-completed questionnaire and, b) for whom concern was listed by the pediatrician, were grouped into a new category as those that had failed both screening instruments. Likewise, those a) who had passed the parent-completed questionnaire and b) for whom no concern was listed by the pediatrician, were grouped into another category as those found normal on both tests. Children that did not fit the criteria for either of these two groups (i.e. they had passed the questionnaire and failed the pediatrician's questionnaire or vice versa) were not included in the calculation. The two groups (one representing children that had passed both questionnaires and the other representing the children that had failed both questionnaires) were compared with the results of the BDI to obtain predictive values. Incorporating the pediatrician's opinion with the results of the questionnaire did not improve the psychometrics of either questionnaire substantially. The exception is 
specificity for the ASQ which improved by .33 , from .39 to .72 . Table 8 summarizes the results of comparing the combined result of the pediatrician's opinion and the screening tool with the BDI.

To be comprehensive, different analyses were attempted such as moving the BDI cut off to one standard deviation below the mean, removing failed communication domains on the ASQ as a potential confounder and redefining a fail for the ASQ as two standard deviations below mean on two or more domains. None of these post-hoc manipulations had a beneficial effect on psychometrics and the results are not included. 


\section{Discussion}

\section{VI.1 Properties of screening tests}

The focus of our study was narrowed to three specific issues:

1) Feasibility of using parent-completed questionnaires in the waiting room.

Establishing the feasibility of these screening tools is of paramount importance. Healthcare professionals have identified cost, time and lack of office staff as barriers to utilizing professionally administered tests. ${ }^{34}$ Therefore, ensuring that parent-completed tests will not incur similar difficulties is a requisite before this screening tool can be further considered. We hypothesized that more than $90 \%$ of parents will complete the developmental screening forms appropriately while waiting in the pediatrician's waiting room.

2) Role of the pediatrician's impression in the screening process.

Pediatricians play an important role in identifying early childhood developmental delay because: a) they may be the only health professionals in contact with the child between birth and 5 years of age ${ }^{17}, b$ ) they have an accepted role of authority, c) they have insight into the child's environment and thus can interpret the child's development and health in the context of the family and social environment ${ }^{18}$, and d) they are identified by law as the chief means to detect this disability. ${ }^{15,16}$ Thus, the potential role of heath-care professionals who are intimately associated with the process of screening to ameliorate screening test's accuracy must be examined. We hypothesized that pediatricians would ameliorate the accuracy of the parent-completed questionnaires. 
3) Accuracy of two parent-completed screening measures- ASQ and CDI.

The test must also be accurate in distinguishing developmentally normal from developmentally abnormal children. The accuracy of screening tests is usually stated in terms of sensitivity and specificity. Sensitivity refers to the proportion of all individuals with the disease that the test will correctly identify; it gives the probability of correctly identifying a diseased individual. Specificity is the proportion of individuals without the condition that the screening test will correctly identify as not having the condition; it gives the probability of correctly identifying a non-diseased individual.

There is a trade off between sensitivity and specificity. A decision as to whether to favor sensitivity (creating more false positives) or to favor specificity (creating more false negatives) must be made by weighing the advantages and disadvantages of a high sensitivity or specificity value. For example, if sensitivity is high (then specificity is lowered) meaning that although one is identifying most delayed children, many are being over-referred. Some of the obvious disadvantages are the costs of additional testing; the additional time spent by health practitioners and the psychological effects on the family due to a misdiagnosis. On the other hand, if specificity is high (then sensitivity is lowered) then most developmentally normal children are recognized as normal but many abnormal children are not being identified; consequently, these children will not have access to intervention programs.

Rough guidelines for sensitivity and specificity values for developmental screening tests have been recommended in the literature. A sensitivity level of 
$70 \%$ or more is acceptable ${ }^{40}$, but some authors recommend levels of $80 \%$ or higher. ${ }^{58}$ Though this signifies that $20-30 \%$ of children will escape detection, if pediatricians follow the recommendation of the American Academy of Pediatrics' Committee on Children with Disabilities to screen at each of the 12 scheduled visits between birth and 5 years of age, these missed cases will be presumably diagnosed in the future. ${ }^{59}$ Similar values are recommended for specificity. Values of $70-80 \%$ are acceptable although some experts recommend nothing less than $90 \%{ }^{36,58}$

Previous studies reported that sensitivity and specificity values for the CDI were moderate to high with one study calculating sensitivity at 0.73 and specificity at $0.87 .{ }^{51}$ For the ASQ, the 18-month questionnaire was composed from the items of the 16-month and the 20-month questionnaire. Taking the mean, sensitivity for the 18-month questionnaire is $0.70(0.73$ and 0.66 for the 16-month and 20-month questionnaire respectively) and specificity is $0.86(0.81$ and 0.90 for the 16 -month and 20 -month questionnaire respectively). ${ }^{56}$ It is important to note that previous studies have tested the accuracy of the ASQ and the CDI in artificial environments with the presence of extra staff or outside of the actual clinic site. ${ }^{20,52}$ Moreover, the population used was pre-screened or/and consisted of small sample size, ranging from 43 to 167 subjects. Consequently, the accuracy of these tests might vary when they are used in the real-life setting of an ambulatory pediatric clinic. ${ }^{49,51,52}$ 


\section{VI.2 Interpretation of results}

Each of these issues can be addressed separately in the context of our results.

1) Feasibility

The participation rate was encouraging. The majority of parents $-95 \%$ for the ASQ and $92 \%$ for the CDI- found the questionnaire either easy or very easy to complete. The completion rate was also high for both questionnaires. That completion was lower for the CDI (75\%) than ASQ (81\%) was to be expected, as the $\mathrm{CDI}$ is longer and more intensive.

More than $75 \%$ of the contacted population was assessed with a standardized screening tool, representing an improved rate to what is currently being achieved with practitioner-administered tests. (Only $23 \%$ of primary-care physicians are regularly using a standardized screening tool.) ${ }^{32}$ Most importantly, one must note that these questionnaires were administered in the clinic at the time of the patient's appointment and did not need the assistance of either office staff or the physician. Because these tests are also cost-effective, the three most frequently mentioned complaints (time, lack of staff and cost) associated with a screening test administered by health-care professionals were overcome.

However, the completion rate was lower than the $90 \%$ completion rate we had hypothesized. In our study, it could have been lowered by the additional burden placed on the parent from the four additional forms placed in the dossier. These additional forms included: a) the consent form; b) the Likert-type questionnaire gathering information about parent's opinion of the standardized 
screening instrument; c) the demographic questionnaire; and d) the one-question questionnaire gathering information about the child's developmental status. Further endeavors can be made to increase the completion rate with active endorsement and encouragement by the primary-care physician and staff; with validation of the usefulness of these questionnaires to monitoring a child's health or with potential incentives (i.e. a gift certificate lottery every year for those that had completed it.)

2) Pediatrician's opinion as a potential modifier

The pediatrician's opinion did not improve the psychometric properties of these questionnaires. The sensitivity for the combined result of the ASQ and the pediatrician's opinion was 0.60 and specificity was 0.73 , while for the combined result of the CDI and pediatrician's opinion, sensitivity was 0.40 and specificity was 0.89 . Consistent with the literature, the pediatrician's opinion had good specificity but poor sensitivity. It is disconcerting that combining the results of a standardized screening tool with the pediatrician's opinion could not produce enhanced and ultimately acceptable sensitivity and specificity values. Perhaps, this indicates the lack of proper health-care training in regards to childhood development. Indeed, the literature has emphasized that there is a gap between the knowledge and skills required in providing developmental services and the limited training that many clinicians receive in this area. This is a problem that appears to have persisted over decades. In 1979 Shonkoff laments: "four fifths of physicians ...viewed their formal training in this area as inadequate... almost $2 / 3$ did not feel that practical experience was an adequate 
substitute for formal training in developmental assessment skills" (page 512). ${ }^{54}$ Such sentiments still persist. A 2000 study performed by the American Academy of Pediatrics found that $64 \%$ of primary care physicians reported inadequate training in developmental assessment. ${ }^{60}$ As a result, an improvement in screening accuracy does not just necessitate more accurate developmental screening tests but also a joint effort from different facets of the professional, public and research community advocating for more thorough training in childhood development and impairments.

3) Accuracy of the two parent-completed measures (ASQ and CDI)

Several studies for both the ASQ and the CDI have advocated their usefulness in screening infants for developmental delay. ${ }^{20,49-52}$ Our results showed that the ASQ had moderate sensitivity (0.67), but poor specificity (0.39). Conversely, the CDI had poor sensitivity (0.50) and good specificity (0.86). Why was the accuracy of these screening instruments lower than expected? Several factors may have played a role.

a) Part of the answer lies in the very nature of development. There are inherent challenges in screening for developmental delay. Firstly, development is a dynamic process that differs from child to child. There are 'normal' differences in the actual times that developmental milestones are reached among children, which is further complicated by the observation that a new skill is expressed inconsistently when first mastered. ${ }^{11,61}$ This, together with the realization that some developmental problems are not apparent early on, simply because it is too early for the function to be clearly evaluated, demonstrates the 
importance of the time of actual assessment and the advantage of regular ongoing multiple screening efforts.

Validating developmental constructs is also problematic. ${ }^{62,63}$ Tests that aim to evaluate the same characteristic may not agree with each other, such as with the Stanford-Binet Intelligence Test which is language based and the Merrill Palmer Intelligence test which uses non-language items to test cognitive abilities. ${ }^{64}$ Finally, developmental screening tests attempt to identify those children with symptoms that are not only subtle, but also blurred by the normal variation among children. Against this clinical backdrop of rapid development followed by slow mastering and consolidation of skills and timelines when functions become sufficiently pronounced for thorough investigation, successful developmental screening poses distinct, practical and pragmatic challenges. ${ }^{63}$ Even though these problems will affect the accuracy of screening for developmental impairments at any age, these difficulties are more pronounced at younger ages when the velocities of development is faster and the number of actual items to test are fewer. ${ }^{63}$ Thus, our study performed at 18-months of age intrinsically created additional challenges that could have lowered the accuracy of these questionnaires.

b) Unlike other projects where the gold standard was applied immediately after the screening instrument, our study imposed a 3-month waiting period representing the real-life wait between screening and referral. A study performed by Darrah J. helps explain how a wait between screening and assessment can lead to lower accuracy. ${ }^{65}$ Darrah assessed infants at 9, 11, 13, 16 
and 21 months for fine motor, gross motor and communication skills. She observed that development was marked by normative instability defined as when one percentile score at a certain age for a certain skill and its $95 \%$ confidence intervals do not overlap with any of the other scores for the same skill set at different time points. ${ }^{65}$ Such a pattern was found for $99 \%$ of children when assessing fine motor skills, $94 \%$ of children when assessing gross motor skills and $40 \%$ of children when assessing communication. ${ }^{65}$ In many cases, $40-60$ percentile rank changes were noted. ${ }^{65}$ Consequently, a wait of three months could result in a different but accurate developmental estimates. Due to the instability of a child's development what might have been identified as a weakness at 18-months of age could have resolved itself by the 21-month age.

c) Another factor that could have affected the screening tool's accuracy may have been the setting in which the questionnaires were completed. Whereas the questionnaires in prior studies were completed in a more controlled setting such as specialty clinics, at home or with the help of staff, this study was performed with no extra resources than those that are normally available in a pediatric ambulatory clinic. The parent was asked to complete the questionnaire in the waiting room and to submit it before their departure. Even though the majority of parents found the questionnaire easy, the environment (i.e. busy waiting room with their child and perhaps other children present) and time constraints surrounding the appointment could have affected the accuracy and the amount of thought the caregivers actually used to answer the questions. 
d) Specifically, the values for the sensitivity of CDI must be interpreted with care. Because there were fewer failures for the CDI and a higher proportion of unreturned questionnaires, the ability of this study to accurately predict the sensitivity of this instrument is limited.

e) Utilizing the ASQ also posed problems. As previously mentioned, we abridged the instructions so that parents would respond to the different items by relying on their impressions and past experiences. Also, the 18-month ASQ was never standardized but rather it was composed of age-appropriate items from the 16-month and 20-month questionnaire. Both of these factors could have affected the accuracy of this screening tool.

Consequently, any of these above factors could have contributed to lower psychometric values than those reported by other researchers.

\section{VI.3 Future Screening Procedures}

It is essential to develop a proper screening agenda. As implied by the results from this study, several significant changes must be incorporated into future screening procedures. Firstly, developmental screening strategies should consider the nature of mental development as a dynamic entity varying from child to child. Therefore, one screening test cannot accurately estimate the course of a child's development. After all, one measurement of the child's height and weight gives little information about the child's overall trajectory of physical development; however, through the course of his or her infancy and childhood various measurements become good indicators of the trajectory of 
physical health. Similarly, calculating accurate mental development will require several samples of the child's ability. The AAP and other researchers have come to the same conclusion. For example, Darrah states screening should involve multiple time points and multiple domains before referrals are made ${ }^{66} \mathrm{~A}$ similar statement was issued by the Committee on Children with Disabilities ${ }^{11}$ : "A single test at one point in time only gives a snapshot of the dynamic, process, making periodic screening necessary to detect emerging disabilities as a child grows" (page 193). Secondly, future screening studies must screen at a younger age. If the infant is screened at 18 months and again at 21 months as follow up to a failed questionnaire then this still is a substantial improvement to the age at which developmental delay is currently being identified and is in-line with the AAP's suggestion and public laws that support identification before the child's second birthday. ${ }^{11,12}$ Finally, the screening instrument must be suited to the environment in which it is to be used. Using parent-completed questionnaires offsets many of the problems with pediatrician-filled tests. As previously mentioned these instruments are time efficient, requiring little staff involvement, are cost-effective, and can be filled out while in the waiting room.

This study lays the foundation from which other objectives and natural correlates can be explored in the future. Firstly and most importantly, there is the possibility of assessing the benefits of two or more serial screening tests at different points in time. Because development, especially at younger ages, is subject to large variability, this second questionnaire (either completed in clinic or sent by mail) has the potential of improving the accuracy of the identification 
process. Secondly, to decrease the amount of time used to score the questionnaire, computer software or programs performing this task could be implemented. This would reinforce the practicality of these types of screening instrument by decreasing the effort from office staff and personnel. Thirdly, a translation of the most useful questionnaire into Canadian French would ensure that an all-inclusive population is screened. Also, the procedure can be adjusted to include different parent-completed screening tests and different gold standards so as to ensure that a thorough picture of available screening tools' strengths and weaknesses are assessed. Finally, a study conducted on a more representative Canadian population incorporating a larger sample size would clarify further issues. It is hoped that the knowledge gained from this study will be used to develop a multi-centered prospective study involving children recruited from a number of geographic locations representing a broad spectrum of socio-economic groups. This longitudinal study would help solidify the best means of identifying early childhood developmental delays.

\section{VI.4 Studv Limitations}

This study has several limitations some of which have already been discussed:

1) The ASQ was used as an in-clinic questionnaire. Though the manual states that it can be used in this fashion, this screening instrument was constructed as a take-home questionnaire such that the parent could attempt the items over several days with the child if need be. By limiting the time to approximately 15 
minutes where the parent must rely on past experiences to answer the items, the accuracy could have been compromised.

2) Altogether only 36 subjects performed the CDI that also performed the BDI. This limits the strength of conclusions for the CDI in particular those for sensitivity since there exists less data for this measure as few subjects actually failed the CDI. Thus, a larger sample size would be needed before drawing definitive conclusions regarding the CDI's performance.

3) The community in which we were conducting the study was predominantly middle class. Consequently, the ability to generalize our results to the overall pediatric population and especially to disadvantaged populations is limited.

4) The CDI and the ASQ are only available in English. This affected participation rate. The caregiver's proficiency and fluency in written English and interpretation of the questions might potentially have affected accuracy.

\section{VI.5 Conclusion}

Developmental delay is a disability that fits into the overall schema of screening for mental health problems. To reaffirm the need of a successful screening strategy for developmental delay, it is useful to review the guidelines for choosing which disabilities to actually screen formulated by Wilson and Jungner. $^{66}$

1) 'The condition sought should be an important health problem.' Developmental disability remains an important health issue with estimates for 
prevalence between $11.8-16.8 \%$ of children during the first 18 years of life. ${ }^{67}$ carrying with it an appreciable burden to the individual, family and society.

2) 'There should be an accepted treatment for patients with the condition.' Developmental delay is not a dichotomous entity with normality (i.e. either/or) and for this reason the term "cure" does not exist when speaking of developmental problems. Nonetheless, intervention services exist that attempt to maximize and optimize developmental achievements and have preliminary indications to improve eventual outcome.

3) 'Facilities for diagnosis and treatment should be available with an agreed policy on whom to treat as patients.' Intervention programs have been made available nationally in the USA through the passing of legislation such as PL99457. ${ }^{12}$ In order to apply these laws, every state in the USA has generated definitions of developmental delay and children who meet this criteria are eligible for state provided intervention services. ${ }^{68}$

4) 'The latent or early symptomatic stage should be known.' Professional organizations have strongly encouraged early identification, focusing on children from birth to 2 years old. Identifying children at this age is possible because an early symptomatic stage can be observed in all the streams of development. It remains the responsibility of the health-care community to develop a protocol which identifies early signs of delay with acceptable accuracy.

5) 'There should be a suitable test or assessment for detecting cases.' Even though there is no gold standard (an ideal test that covers all areas of 
development, that is equally applicable to all ages, that is both reliable and valid, and that has an accuracy approaching values of $100 \%$ for sensitivity and specificity), there are assessments such as the BDI and the BSID that are well standardized, having acceptable levels of sensitivity and specificity in the context of documented developmental delays. The screening tests are also valid and reliable.

6) 'The test should be acceptable to the population.' Screening tests are well tolerated by the child and parents, being non-invasive and time-efficient.

7) 'The natural history of the condition should be adequately understood.' Developmental delay has many different trajectories that do not share one history of manifestation from the latent to declared disorder. The trajectory followed varies depending on the precise type of neurodevelopmental disability and the individual affected.

8) 'The costs of case-finding and expenditure on treatment should be economically balanced with the benefits to the individual and society.' Costbenefit analysis has demonstrated that the monetary value of the benefits far surpasses the costs. The effects of investment into an at-risk child's development remain apparent into adulthood and create important differences with those children who did not receive intervention. For example, the evidence that early intervention with poverty-stricken children increases academic and non-academic success is quite strong. ${ }^{13}$ A comprehensive study, the Perry School study, estimated that 2 years in an early intervention programs (at age 3 and 4) could save society up to $\$ 100,000$ per child enrolled. ${ }^{13}$ Therefore, the 
costs are far less than the economic benefits that society experiences as a result of fewer arrests, fewer individuals receiving welfare and higher gross earnings.

9) 'Case-finding should be a continuous process and not "a once and for all" project.' Law and professional societies have both encouraged primary care physicians to screen all children and it is realized that a "once and for all" process of case-finding will not fulfill the goals championed by professional societies and child advocates.

Because developmental delay does fit well with the overall schema of screening for mental health problems, the imperative question that arises is how to recognize developmentally delayed individuals systematically and comprehensively. This challenge has been partially answered by the formulation and standardization of developmental screening tests. Nevertheless, difficulties remain concerning the feasibility of such tests in practical settings such as the busy pediatric clinic. It is realized that an effective and complete paradigm includes proper screening instruments, optimal timing of assessment and use of proper identification strategies and intervention strategies to maximize the potential of all children. 


\section{Tables and Figures}

\begin{tabular}{|c|c|}
\hline Disability & Description \\
\hline Gross Motor Delay & $\begin{array}{l}\text { Significant delay in fine or gross motor skills with no } \\
\text { impairment in other developmental areas }\end{array}$ \\
\hline $\begin{array}{l}\text { Developmental Language } \\
\text { Disorders } \\
\text { (specific language disorders) }\end{array}$ & $\begin{array}{l}\text { Significant delay in receptive and/or expressive language } \\
\text { skills with no delay in other developmental domains }\end{array}$ \\
\hline Global developmental delay & $\begin{array}{l}\text { Significant delay in two or more developmental streams } \\
\text { as measured by appropriate standardized screening tests. } \\
\text { This term is reserved for children less than } 5 \text { years of } \\
\text { age. }{ }^{9}\end{array}$ \\
\hline Cerebral Palsy & $\begin{array}{l}\text { Early-onset non progressive motor impairment with } \\
\text { associated abnormalities in muscle tone }\end{array}$ \\
\hline $\begin{array}{l}\text { Primary Sensory Impairments } \\
\text { - Visual } \\
\text { - Hearing }\end{array}$ & $\begin{array}{l}\text { Vistal impairment: An optically or medically diagnosable } \\
\text { condition in the eye(s) or visual system that affects the } \\
\text { development and normal use of vision ranging from slight } \\
\text { to complete blindness. } \\
\text { Hearing impairments: a reduction in the ability to hear } \\
\text { sound ranging from slight to complete deafness. }{ }^{69}\end{array}$ \\
\hline $\begin{array}{l}\text { School related } \\
\text { - ADHD } \\
\text { - Learning Disabilities }\end{array}$ & $\begin{array}{l}A D H D \text { : A persistent pattern of inattention and/or } \\
\text { hyperactivity that is expressed with higher frequency and } \\
\text { severity than normally found in the population. } \\
\text { Learning disabilities: Significantly lowered individual } \\
\text { achievement than normal as measured by standardized } \\
\text { tests assessing reading, mathematics or written expression }\end{array}$ \\
\hline $\begin{array}{l}\text { Autistic spectrum disorders: } \\
\text { - Pervasive developmental } \\
\text { delay } \\
\text { - Pervasive developmental } \\
\text { disorders not otherwise } \\
\text { specified }\end{array}$ & $\begin{array}{l}\text { Pervasive developmental delay (PDD): Impairments in } \\
\text { social or communication skills or restrictive/repetitive } \\
\text { patterns of behaviour. } \\
\text { Pervasive developmental disorders not otherwise } \\
\text { specified: similar to PDD but not enough symptoms to } \\
\text { warrant a PDD diagnosis. }{ }^{70}\end{array}$ \\
\hline
\end{tabular}

('Significant' is usually operationalized to represent a performance on standardized, ageappropriate and norm-referenced tests that is more than two standard deviations below mean.)

\section{Table 1}

Classification of Developmental Delay 


\begin{tabular}{|c|c|c|c|c|c|}
\hline & Objectives & $\begin{array}{c}\text { Sample } \\
\text { Size }\end{array}$ & Cohort & $\begin{array}{c}\text { Age } \\
\text { (mean) }\end{array}$ & Gold Standard \\
\hline \multicolumn{6}{|l|}{ ASO } \\
\hline $\begin{array}{l}\text { Skellern CY et al, } 2001^{49} \\
\text { A parent-completed developmental } \\
\text { questionnaire: Flow-up of ex } \\
\text { premature infants }\end{array}$ & Testing predictive value & 167 & \begin{tabular}{|c|} 
Ex- \\
premature \\
( $\leq 31$ weeks \\
gestation) \\
\end{tabular} & $\begin{array}{l}12,18,24 \\
48 \text { months }\end{array}$ & $\begin{array}{l}\text { Griffith Mental Development Scales, Bayley } \\
\text { Mental Development Intelligence Scale, } \\
\text { McCarthy General Intelligence Scale }\end{array}$ \\
\hline $\begin{array}{l}\text { Squires J, et al, } 1997^{\text {so }} \\
\text { Revision of a parent-completed } \\
\text { developmental screening tool: ASQ }\end{array}$ & Testing validity and reliability & 2,008 & Community & \begin{tabular}{|c|}
$4,8,12$ \\
$16,20,24$ \\
30,36 \\
months \\
\end{tabular} & \begin{tabular}{|c|} 
Bayley Scales of Infant Development (BSID), \\
Gesell Developmental Schedules, Standford- \\
Binet Intelligence Scale, McCarthy Scales of \\
Children's Abilities
\end{tabular} \\
\hline \multicolumn{6}{|l|}{$\underline{\text { CDI }}$} \\
\hline $\begin{array}{l}\text { Ireton } \mathrm{H} \text { et al, } 1995^{20} \\
\text { Assessing children's development } \\
\text { using parent's reports- the CDI }\end{array}$ & Testing reliability and validity & 568 & Community & $\begin{array}{c}15 \text { months } \\
\text { to } 5 \mathrm{yrs}\end{array}$ & Age, academic achievement \\
\hline $\begin{array}{l}\text { Montgomery ML et al, } 1999^{51} \\
\text { Use of the CDI to screen high-risk } \\
\text { populations }\end{array}$ & Testing predictive value & 76 & High-risk* & 33.7 & $\begin{array}{c}\text { Clinical Adaptive Test/ Clinical Linguistic and } \\
\text { Auditory Milestone Scale (CAT/CLAMS) } \\
\begin{array}{c}\text { Slosson Intelligence Test- both are screening } \\
\text { instruments }\end{array} \\
\end{array}$ \\
\hline $\begin{array}{l}\text { Doig KB et al, } 1999^{52} \\
\text { The CDI: A developmental outcome } \\
\text { measure for follow-up of the high risk } \\
\text { infant }\end{array}$ & Testing predictive value & 43 & High-risk* & 25.5 & $\begin{array}{c}\text { Clinical Adaptive Test/ Clinical Linguistic and } \\
\text { Auditory Milestone Scale (CAT/CLAMS) } \\
\text { Bayley Scales of Infant Development-II } \\
\text { (BSID-II), }\end{array}$ \\
\hline
\end{tabular}

"birthweight $\leq 1500 \mathrm{~g}$, mechanical ventilation for 7 days or less, status post extracorporeal membrane oxygenation (ECMO), neonatal asphyxia, Apgar less that 5 at 5 mimutes, cocaine exposure in utero, neonatal seizures or small for gestational age.
Table 2

Table summarizing previous studies utilizing the Ages and Stages Questionnaire (ASQ) and the Child Development Inventory (CDI). Common shortfalls in these studies are small sample sizes, using specific cohorts, using subjects older than two years of age and validating screening instruments with other screening instruments. 


\begin{tabular}{|c|c|c|c|}
\hline Characteristics & $\frac{\text { True participants }}{\mathrm{N}(\%)}$ & $\begin{array}{c}\begin{array}{c}\text { False } \\
\text { Participants }\end{array} \\
N(\%)\end{array}$ & $\frac{\text { Refusal }}{\mathrm{N}(\%)}$ \\
\hline \multicolumn{4}{|l|}{ Responding parent } \\
\hline $\begin{array}{l}\text { Mother } \\
\text { Father } \\
\text { Other }\end{array}$ & $\begin{array}{c}223(90) \\
19(8) \\
6(2)\end{array}$ & $\begin{array}{l}\text { N/A } \\
\text { N/A } \\
\text { N/A }\end{array}$ & $\begin{array}{l}\text { N/A } \\
\text { N/A } \\
\text { N/A }\end{array}$ \\
\hline \multicolumn{4}{|l|}{$\frac{\text { Education-last year of }}{\text { school completed }}$} \\
\hline $\begin{array}{c}\text { (mother/father) } \\
\text { High school incomplete }\end{array}$ & $\begin{array}{c}\mathrm{N}=243 \\
3(1) / 2(1)\end{array}$ & $\begin{array}{c}N=17 \\
2(12) / 0(0)\end{array}$ & $\begin{array}{c}N=23 \\
1(4) / 1(4)\end{array}$ \\
\hline $\begin{array}{c}\text { High School } \\
\text { CEGEP/College }\end{array}$ & $\begin{array}{c}18(7) / 28(12) \\
80(33) / 76(32)\end{array}$ & $\begin{array}{l}3(18) / 2(12) \\
4(24) / 3(18)\end{array}$ & $\begin{array}{l}3(13) / 3(13) \\
4(17) / 8(35)\end{array}$ \\
\hline $\begin{array}{l}\text { University } \\
\text { Graduate school }\end{array}$ & $\begin{array}{c}116(47) / 102(42) \\
26(11) / 33(14)\end{array}$ & $\begin{array}{c}7(41) / 11(65) \\
1(6) / 1(6)\end{array}$ & $\begin{array}{c}10(44) / 10(44) \\
5(22) / 1(4)\end{array}$ \\
\hline Working mother & $\mathrm{N}=248$ & $\mathrm{~N}=17$ & $\mathrm{~N}=23$ \\
\hline Yes & $159(64)$ & $10(59)$ & $13(57)$ \\
\hline \multicolumn{4}{|l|}{ Combined income for } \\
\hline the household & $\mathrm{N}=228$ & $\mathrm{~N}=12$ & $\mathrm{~N}=21$ \\
\hline$\$ 0-19,000$ & $6(3)$ & $0(0)$ & $2(10)$ \\
\hline$\$ 20,000-39,999$ & $14(7)$ & $1(8)$ & $0(0)$ \\
\hline$\$ 40,000-59,999$ & $23(10)$ & $2(17)$ & $8(37)$ \\
\hline$\$ 60,000-79,999$ & $45(19)$ & $1(8)$ & $2(10)$ \\
\hline$\$ 80,000$ and above & $140(61)$ & $8(67)$ & $9(43)$ \\
\hline
\end{tabular}

\section{Table 3}

Demographic data for three populations: true participants, false participants (those who agreed to participate over the phone but who never returned the questionnaire), and refusals. 


\begin{tabular}{|c|c|c|c|}
\hline & $\begin{array}{c}\text { True } \\
\text { Participants }\end{array}$ & $\begin{array}{c}\text { False } \\
\text { Participants }\end{array}$ & Refusal \\
\hline Child Gender & $\mathbf{N}(\%)$ & $\mathbf{N}(\%)$ & $\mathbf{N}(\%)$ \\
\hline Male & $132(53)$ & 34 (53) & $22(56)$ \\
\hline Female & $116(47)$ & $30(47)$ & $17(44)$ \\
\hline \multicolumn{4}{|l|}{ Age (months) } \\
\hline Mean $\pm S D$ & $18.4 \pm .64$ & $\mathbf{N} / \mathbf{A}$ & $\mathbf{N} / \mathbf{A}$ \\
\hline Range & $17.03-20.47$ & $\mathbf{N} / \mathbf{A}$ & $\mathbf{N} / \mathbf{A}$ \\
\hline \multicolumn{4}{|l|}{ Gestational Age } \\
\hline Weeks \pm SD & $38.6 \pm 2.0$ & $39.0 \pm 2.7$ & $38.5 \pm 2.5$ \\
\hline $\begin{array}{c}\text { Pre-term }(<36) \\
\text { N }(\%)\end{array}$ & $20(8)$ & $3(5)$ & $2(6)$ \\
\hline $\begin{array}{c}\text { Term }(>36) \\
N(\%)\end{array}$ & $218(92)$ & $56(95)$ & $33(94)$ \\
\hline
\end{tabular}

\section{Table 4}

Descriptive data showing the mean age and range of the infants participating in this study. Other data (gestational age and gender distribution) is also given for three groups: true participants, false participants and refusals. 
A)

\begin{tabular}{cccc} 
Domain & ASQ & Agreement & BDI \\
\hline Communication & 36 & 10 & 13 \\
Gross Motor & 1 & 1 & 7 \\
Fine Motor & 2 & 0 & 0 \\
Problem-solving & 6 & 0 & 5 \\
Social & 2 & 0 & 2 \\
\hline
\end{tabular}

B)

\begin{tabular}{|c|c|c|c|}
\hline Domain & CDI & Agreement & $\underline{\text { BDI }}$ \\
\hline Social & 1 & 0 & 0 \\
\hline Self-help & 0 & 0 & 0 \\
\hline Gross motor & 3 & 3 & 3 \\
\hline Fine motor & 1 & 0 & 0 \\
\hline $\begin{array}{l}\text { Expressive language } \\
\text { and Comprehension }\end{array}$ & 3 & 1 & 3 \\
\hline Global Development & 1 & 0 & 2 \\
\hline
\end{tabular}

Table 5

Description of the agreement between the domains of the questionnaires and the Battelle Developmental Inventory (BDI)

A) The first numerical column represents the number of infants that failed the domain on the ASQ. The last column represents the number of infants that failed the domain for the BDI. The middle column represents the agreement between the ASQ and BDI- the number of times the child failed both the screening instrument and assessment

B) The first numerical column represents the number of infants that failed the domain on the ASQ. The last column represents the number of infants that failed the domain for the BDI. The middle column represents the agreement between the CDI and BDI- the number of times the child failed both the screening instrument and assessment. 


\section{ASQ $n=183$}

165 questionnaires distributed

134 completed $(81 \%)$

- 37 returned late $(22 \%)$

28 questionnaires unreturned $(17 \%)$

3 questionnaires incomplete (2\%)

\section{CDI $n=171$}

152 questionnaires distributed

114 completed $(75 \%)$

- 41 returned late $(27 \%)$

36 questionnaires unreturned $(23 \%)$

2 questionnaires incomplete (2\%)

\begin{tabular}{|c|c|c|c|}
\hline \multicolumn{2}{|c|}{$\begin{array}{c}\frac{\text { Parent's opinion of }}{\text { questionnaire }} \\
\mathrm{N}=1 \\
\begin{array}{c}\text { Mean }=1.5 \pm .6 \\
\text { n (\%) }\end{array}\end{array}$} & \multicolumn{2}{|c|}{$\begin{array}{c}\frac{\text { Parent's opinion of }}{\text { questionnaire }} \\
\mathrm{N}=112 \\
\text { Mean=1.6 } \\
\text { n (\%) }\end{array}$} \\
\hline Very easy & $75(57)$ & Very easy & $54(48)$ \\
\hline Easy & $50(38)$ & Easy & 49 (44) \\
\hline Neutral & $6(5)$ & Neutral & $8(7)$ \\
\hline Difficult & $1(1)$ & Difficult & $1(1)$ \\
\hline Very Difficult & $\mathbf{0}$ & Very Difficult & $\mathbf{0}$ \\
\hline
\end{tabular}

\section{Table 6}

Completion rate and the parental ranking of the ASQ and the CDI. To collect data on the parent's opinion of the questionnaire, the question-" Did you find this questionnaire easy to complete? Place a check mark in the box that corresponds to your answer"- was asked. The number and types of responses are listed. 
A)

\begin{tabular}{|c|c|c|c|c|}
\hline & & \multicolumn{2}{|c|}{ BDI } & \\
\hline & & Fail & Pass & Total \\
\hline \multirow{2}{*}{ ASQ } & Fail & 14 & 27 & 41 \\
\cline { 2 - 5 } & Pass & 7 & 17 & 24 \\
\hline & TOTAL & 21 & 44 & 65 \\
\hline
\end{tabular}

Sensitivity $\quad 0.67$

Specificity $\quad 0.39$

PV+ $\quad 0.34$

PV- $\quad 0.71$

B)

\begin{tabular}{|c|c|c|c|c|c|c|}
\hline & & \multicolumn{2}{|c|}{ BDI } & \multirow[b]{2}{*}{ Total } & \multirow{2}{*}{$\begin{array}{l}\text { Sensitivity } \\
\text { Specificity }\end{array}$} & \multirow{2}{*}{$\begin{array}{l}0.50 \\
0.86\end{array}$} \\
\hline & & Fail & Pass & & & \\
\hline \multirow{3}{*}{ CDI } & Fail & 4 & 4 & 8 & PV+ & 0.50 \\
\hline & Pass & 4 & 24 & 28 & \multirow[t]{2}{*}{ PV- } & 0.86 \\
\hline & TOTAL & 8 & 28 & 36 & & \\
\hline
\end{tabular}

Table 7

Psychometric values (sensitivity, specificity, positive predictive value $(\mathrm{PV}+)$, negative predictive value (PV-) for:
A) ASQ
B) $\mathrm{CDI}$ 
A)

\begin{tabular}{|c|c|c|c|c|c|c|}
\hline & & \multicolumn{2}{|c|}{ BDI } & & \multirow{2}{*}{$\begin{array}{l}\text { Sensitivity } \\
\text { Specificity }\end{array}$} & 0.60 \\
\hline & & Fail & Pass & Total & & 0.73 \\
\hline \multirow{3}{*}{$\begin{array}{c}\text { Ped and } \\
\text { ASQ }\end{array}$} & Fail & 9 & 6 & 15 & PV+ & 0.60 \\
\hline & Pass & 6 & 16 & 22 & \multirow{2}{*}{ PV- } & 0.73 \\
\hline & TOTAL & 15 & 22 & 36 & & \\
\hline
\end{tabular}

B)

\begin{tabular}{|c|c|c|c|c|c|c|}
\hline & & \multicolumn{2}{|c|}{ BDI } & \multirow[b]{2}{*}{ Total } & \multirow{2}{*}{$\begin{array}{l}\text { Sensitivity } \\
\text { Specificity }\end{array}$} & \multirow{2}{*}{$\begin{array}{l}0.40 \\
0.89\end{array}$} \\
\hline & & Fail & Pass & & & \\
\hline \multirow{3}{*}{$\begin{array}{c}\text { Ped and } \\
\text { CDI }\end{array}$} & Fail & 2 & 3 & 5 & PV+ & 0.40 \\
\hline & Pass & 3 & 23 & 26 & PV- & 0.89 \\
\hline & TOTAL & 5 & 26 & 31 & & \\
\hline
\end{tabular}

Table 8

Psychometric values after incorporating the results of the parent-completed questionnaire (ASQ or CDI) with pediatrician's opinion (Ped):

A) Combined ASQ and pediatrician's opinion compared with the BDI

B) Combined CDI and pediatrician's opinion compared with BDI 


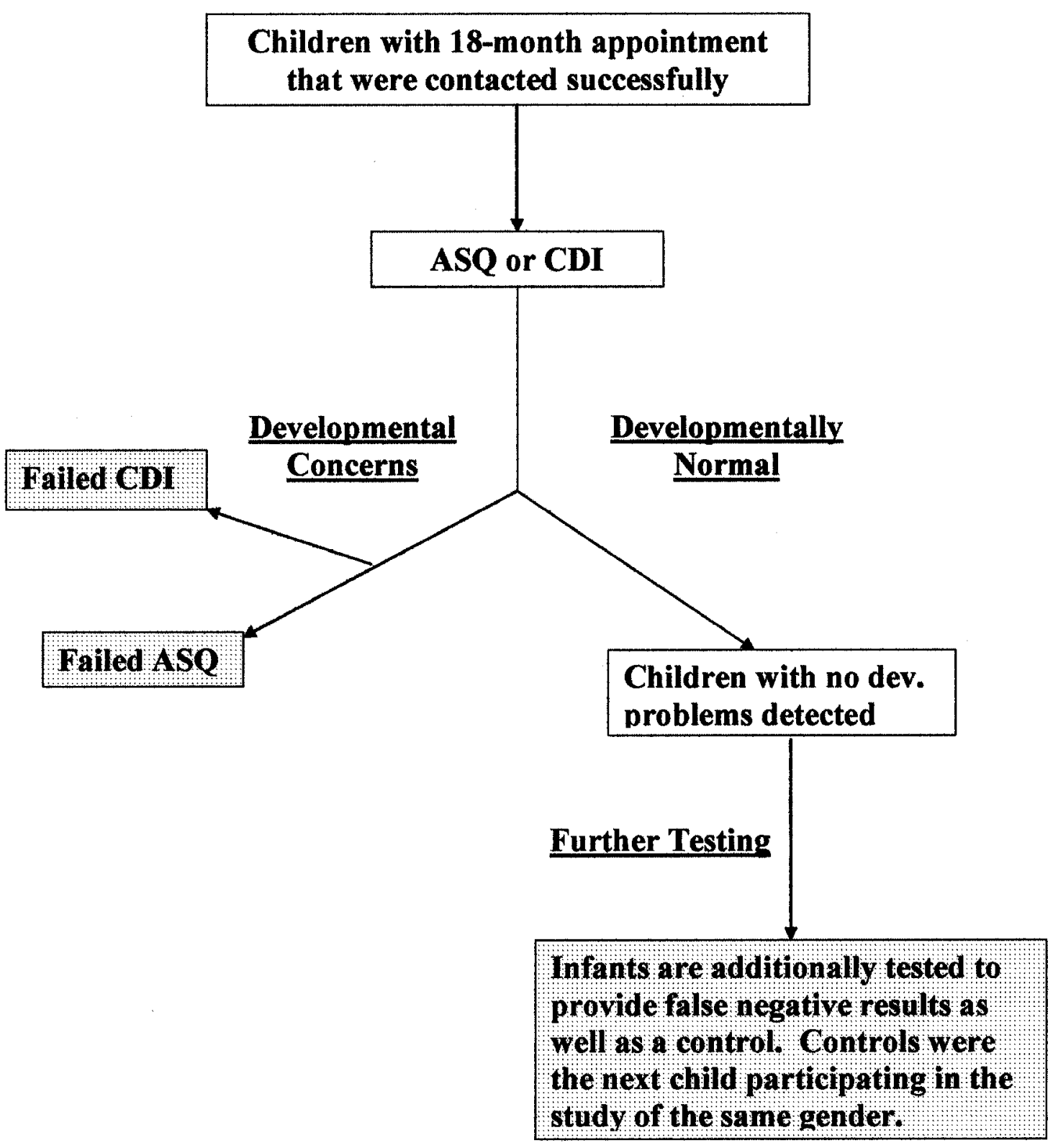

\section{Figure 1}

Flow Chart demonstrating the breakdown of subjects in this study. The shaded areas represent children who were also assessed by the Battelle Development Inventory (BDI). 


\section{References}

1. Shevell MI, Majnemer A, Rosenbaum P, Abrahamowicz M: Profile of referrals for early childhood developmental delay to ambulatory subspecialty clinics. $J$ Child Neurol 2001;16: 645-650.

2. Fenichel GM. Psychomotor retardation and regression. In: Clinical Pediatric Neurology: signs and symptoms approach, $4^{\text {th }}$ ed. Philadelphia, WB Saunders, 2001, pp 117-147.

3. Simeonsson RJ, Simeonsson NW. Developmental surveillance and intervention. In: Hoekelman RA, Adam HM, Nelson NM, et al (eds): Primary Pediatric Care, $4^{\text {th }}$ ed. St. Louis: Mosby, 2001, pp274-282.

4. Kinsbourne M, Graf WD: Disorders of mental development. In: Menkes JH, Sarnat HB (eds): Child Neurology, $6^{\text {th }}$ ed. Philadelphia: Lippincott Williams \& Wilkins, 2001, 1155-1211.

5. Batshaw ML, Shapiro BK: Mental Retardation. In Batshaw (eds): Children with Disabilities, $4^{\text {th }}$ ed. Baltimore, Paul H. Brookes, 1997, pp335-359.

6. Majnemer A, Shevell MI: Diagnostic yield of neurologic assessment of the developmentally delayed child. J Pediatr 1995;127:193-199.

7. First LR, Palfrey JS: The infant or young child with developmental delay. New Eng JMed 1994;330:478-483.

8. Wolraich ML: Disorders of development and learning, ed 3. Hamilton, BC Decker Inc, 2003.

9. Shevell MI: Evaluating childhood development delay. Neurology Rounds $2004 ; 21-6$ 
10. Simeonsson RJ, Sharp MC: Developmental delays, in Hoekelman RA, Friedman SB, Nelson NM, et al (eds): Primary Pediatric Care. St Louis, MosbyYearbook, 1992, pp 867-870.

11. American Academy of Pediatrics-Committee on Children With Disabilities: Developmental surveillance and screening of infants and young children. Pediatrics 2001;108:192-196.

12. Majnemer A: Benefits of early intervention for children with developmental disabilities. Semin Pediatr Neurol 1998;5:62-69.

13. Sharkey MA, Palitz ME, Reece LF et al: The effect of early referral and intervention on the development disabled infant: evaluation at 18 months of age. J Am Board Fam Pract 1990;3:163-170

14. Palfrey JS. Legislation for the education of children with disabilities, in Levine MP, Carey WB, Crocker AC (eds): Developmental-behavioral pediatrics, $2^{\text {nd }}$ ed. Philadelphia: WB. Sanders Company. 1992, pp 782-85.

15. Individuals With Disabilities Education Act Amendments of 1997 (Pub L No.105-107).

16. Squires J, Nickel RE, Eisert D: Early Detection of Developmental Problems: Strategies for Monitoring Young Children in the Practice Setting. J Dev Behav Pediatr 1996;17:420-427.

17. Gilbride KE: Developmental Testing. Pediatr Rev 1995;16:338-346.

18. Dworkin PH, Glascoe FP: Early Intervention of developmental delays: How do you measure up? Contemp Pediatr 1997;14:158-168. 
19. Dworkin PH: Developmental Screening-Expecting the Impossible? Pediatrics $1989 ; 83: 619-622$.

20. Ireton H, Glascoe FP: Assessing children's development using parent's reports: The Child Developmental Inventory. Clin Pediatr 1995;34:248-255.

21. Glascoe FP, Dworkin PH: Obstacles to effective developmental surveillance: errors in clinical reasoning. $J$ Dev Behav Pediatr 1993;14:344-349.

22. Glascoe FP: Early detection of developmental and behavioral problems. Pediatrics Rev 2000;21:272-279.

23. Dulcan MK, Costello EJ, Costello AJ, Edelbrock C, et al: The pediatrician as gatekeeper to mental health care for children: Do parents' concerns open the gates? J Am Acad Child Adolesc Psychiatry 1990;29:453-458.

24. Johnson CP: Using developmental and behavioral screening tests. Pediatr Rev $2000 ; 21: 255-256$

25. Dutton DB: Patterns of ambulatory health care in five different delivery systems. Med Care 1979;17:221-243.

26. Reisgner KS, Bires JA: Anticipatory guidance in pediatric practice. Pediatrics $1980 ; 66: 889-892$

27. Rainbault G, Cachin O, Limala JL, et al: Aspects of communication between parents and doctors: An analysis of the discourse in medical interviews. Pediatrics 1975;55:401-405.

28. American Academy of Pediatrics-Committee on Children With Disabilities: Screening infants and young children for developmental disabilities. Pediatrics $1994 ; 93: 863-865$ 
29. Dearlove J, Kearney D: How good is general practice developmental screening? Br Med J 1990;300:1177-1180.

30. Dobos AE, Bernstein BA: Pediatricians' approach to developmental problems: Has the gap been narrowed? Dev Behav Pediatr 1994;15:34.

31. Gardner W, Kelleher KJ, Pajer KA, Campo JV: Primary care clinicians' use of standardized tools to assess child psychosocial problems. Ambul Pediatr 2003;3:191-195.

32. Sand N, Silverstein M, Glascoe FP, Gupta VB, Tonniges TP, O'Connor, KG. Pediatricians' reported practices regarding developmental screening: do guidelines work? Do they help? Pediatrics. 2005;116:174-179.

33. Sices L, Feudtner C, McLaughlin J, et al: How do primary-care physicians identify young children with developmental delays? A National Survey. J Dev Behav Pediatr 2003;24:409-417.

34. Division of Health Policy Research: Identification of Children $<36$ months at risk for developmental problems and referral to early identification programs. American Academy of Pediatrics, Periodic Survey of Fellows, 2003 available at: www.aap.org/research/periodicsurvey/ps53exs.htm Accessed July 14, 2004.

35. Knolbosch H, Stevens F, Malone A, et al: The validity of parental reporting of infant development. Pediatrics 1979;63:872-878.

36. Glascoe FP: Parents' concerns about children's development: Prescreening technique or screening test. Pediatrics 1997;99:522-528.

37. Glascoe FP, Alteimer WA, MacLean WE: The importance of parent's concerns about their child's development. Am J Dis Child 1989;143:955-958. 
38. Glascoe FP, MacLean WE, Stone WL: The importance of parent's concerns about their child's behavior. Clin Pediatr 1991;30:8-14.

39. Glascoe FP: It's not what it seems. The relationship between parent's concerns and children with global delays. Clin Pediatr 1994;33:292-296.

40. Glascoe FP, Dworkin PH: The role of parents in the detection of developmental and behavioral problems. Pediatrics 1995;95:829-836.

41. Glascoe FP: Parents' Evaluation of Developmental Status: how well do parents' concerns identify children with behavioral and emotional problems? Clin Pediatr 2003;42:133-138.

42. Glascoe FP: Are over-referrals on developmental screening test really a problem? Arch Pediatr Adolesc Med 2001;155:54-59.

43. Rescorla L: The Language Development Survey: a screening tool for delayed language in toddlers. J Speech Hear Disord 1989;54:587-599.

44. Diamond KE, LeFurgy W: Relationships between mother's expectations and the performance of their infants with developmental handicaps. Am J Ment Retard 1992;92:11-20.

45. Dale P, Bates E, Reznick S, Morisset C: The validity of parent report instrument of child language at twenty months. J Child Lang 1989:16:239-249.

46. Hickson GB, Alteimer WA, O'Connor S: Concerns of mothers seeking care in private pediatric offices: opportunities for expanding services. Pediatrics $1983 ; 72: 619-624$. 
47. Dobrez D, Lo Sasso A, Holl J, et al: Estimating the cost of developmental and behavioral screening of preschool children in general pediatric practice. Pediatrics 2001;108:913-922.

48. Regalado M, Halfon N: Primary care services promoting optimal child development from birth to age 3 years. Ach Pediatr Adolesc Med $2001 ; 155: 1311-1322$.

49. Skellern CY, Rogers Y, O'Callaghan MJ: A parent-completed developmental questionnaire: Follow up of ex-premature infants. $J$ Paediatr Child Health 2001;37: 125-129.

50. Squires J, Bricker D, Potter L: Revision of a parent-completed developmental screening tool: Ages and Stages Questionnaire. J Pediatr Psychol 1997;2:313328.

51. Montgomery ML, Saylor CF, Bell NL, et al: Use of the Child Development Inventory to screen high-risk populations. Clinic Pediatr 1999;38:535-539.

52. Doig KB, Marcias MM, Saylor CF, et al: The Child Development Inventory: A developmental outcome measure for follow up of the high-risk infant. J Pediatr $1999 ; 135: 358-362$.

53. Sonnander K: Early identification of children with developmental disabilities. Acta Paediatr Suppl 2000;434:17-23.

54. Shonkoff JP, Dworkin PH, Leviton A Levine MD: Primary approaches to developmental disabilities. Pediatrics 1979;64:506-514.

55. Newborg J, Stock JR, Wnek L, Guidubaldi J, Svinicki J. Battelle Developmental Inventory:Examiner's Manual. Allen, TX:DLM LINC Associates;1984. 
56. Squires J, Potter L, Mounts L: ASQ User's Guide for the Ages and Stages Questionnaire, ed 2. Baltimore, Brookes, 1997.

57. Ireton H: Child Development Inventories Manual. Minneapolis, Behavior Science Systems, 1992.

58. Barnes KE: Preschool Screening: The measurement and prediction of children at risk. Springfield, Charles C Thomas Publishers, 1982.

59. American Academy of Pediatrics-Committee on Children with Disabilities: Screening for developmental disabilities. Pediatrics 1986;78:526-528.

60. American Academy of Pediatrics: Barriers to developmental screening according to pediatricians: Results from AAP surveys of pediatricians. 2000: http://www.cdc.gov/ncbddd/child/DSbarriersrpt.pdf

61. Darrah J, Redfern L, Maguire TO, et al: Intra-individual stability of rate of gross motor development in full term infants. Early Hum Dev 1998:52;169-179.

62. Majnemer A, Mazer B: Neurological evaluation of the newborn infant: Definition and psychometric properties. Dev Med Child Neurol 1998;40:708715.

63. Aylward GP: Conceptual issues in developmental screening and assessment. Dev Behav Pediatr 1997;18:340-349.

64. Frankenburg WK: Preventing developmental delays: Is developmental screening sufficient? Pediatrics 1994;93:586-589.

65. Darrah J, Hodge m, Magill-Evans J, Kembhavi G: Stability of serial assessments of motor and communication abilities in typically developing infantsimplications for screening. Early Hum Dev 2003;72:97-110. 
66. Wilson JMG, Jungner G: Principles of screening for disease. Geneva, World Health Organization, 1968, pp 26-39.

67. King-Thomas L, Hacker BJ: A Therapist's Guide to Pediatric Assessment. Toronto, Little, Brown and Company, 1987.

68. Brigance A, Glascoe FP: Brigance Infant and Toddler Screens, North Billerica, Curriculum Associates, 2002.

69. Nuttall EV, Romero I, Kalesnik J: Assessing and screening preschoolers. Needham, Allyn and Bacon, 1992, pp 327-368.

70. American Psychiatric Association-Task force on DSM IV: Diagnostic and Statistical Manual of Mental Disorders-TR, Washington, American Psychiatric Association, 2000 


\section{GENERAL INFORMATION}

Mother's Education

Last year of schooling completed:

High school incomplete

High school

CEGEP/ College

University degree

Graduate degree

Mother Employed (paid) $\square$ yes $\square$ no Occupation:
Father's Education

Last year of schooling completed:

$\square$ High school incomplete

$\square$ High school

$\square$ CEGEP/College

$\square$ University degree

Graduate degree

What income range best corresponds to the combined inceme (before taxes) for the household?

$0-\$ 19,999$

$\$ 60,000-79,000$

Postal Code:

Reason for not completing questionnaire (during time at the clinic):
$\$ 40,000-\$ 59,000$

$\$ 80,000$ and above
Father Employed (paid) $\square$ yes $\square$ no Occupation:

\section{Appendix 2}

Short demographic questionnaire 


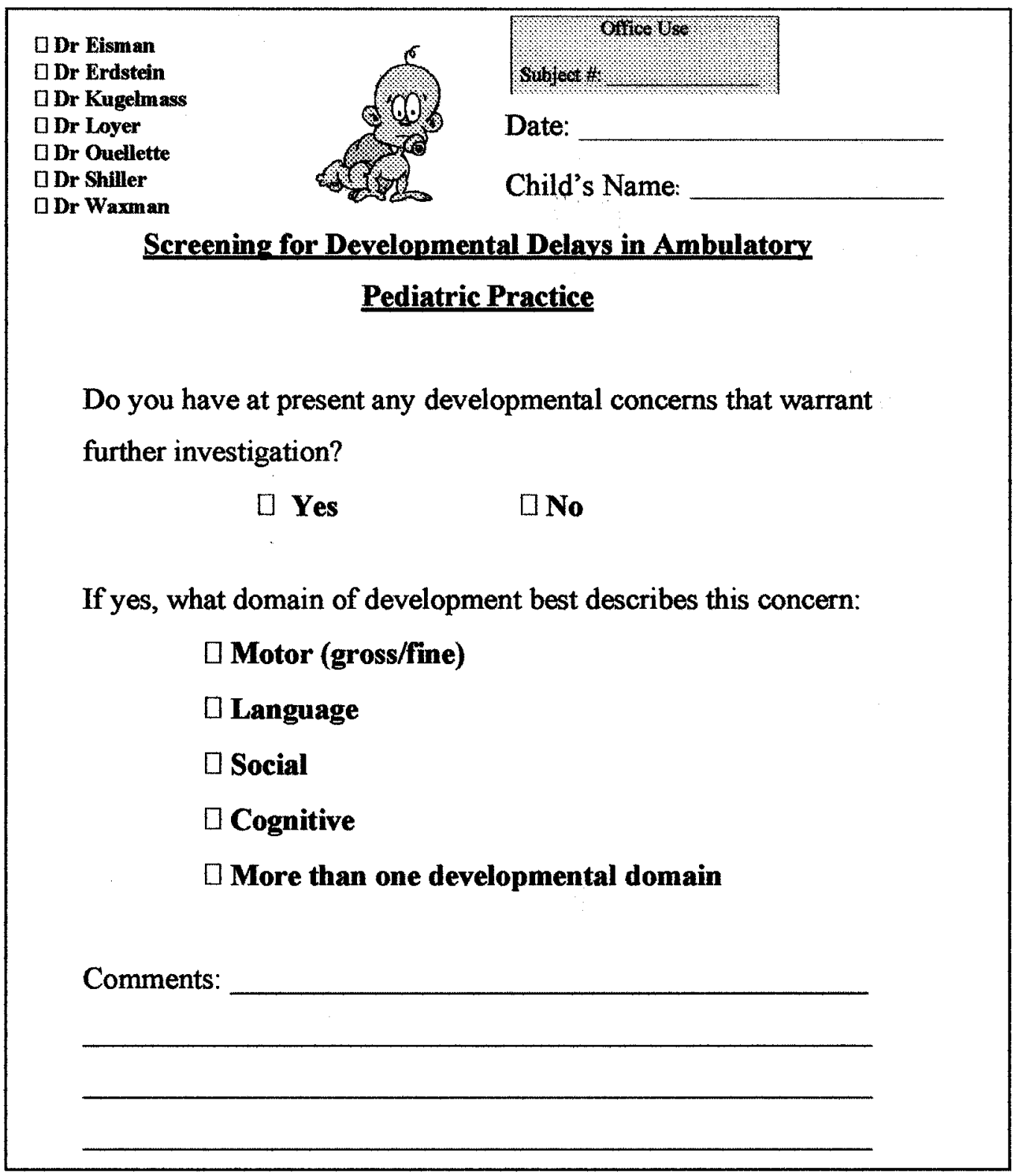

\section{Appendix 3}

Questionnaire completed by pediatrician (and parent) 
Centre univensitaire de vante Mcoull

McGill University Heaith Centre

Screnening of Eaxly Developmental Concems Study

Consent frimm arid information sheet

principal investigatur:

Dr. Micinel Shevell, Division of Perbiartic Neurslogy. Montreal Cinituren's Hospital.

The office visit for your child at 18 months of age is part of routine welthaby care. it coincides

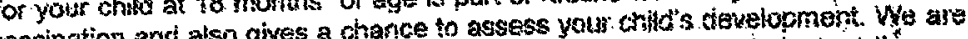
with a time for vaccination and also gives a chance to assess you child in our stidy to bos at the use asking fo you would be wiling to participate along with sour chit.

of quastionnetres to assess possitse a

As part of this study, you with be asked to complote a simple quesionnitire, which takes 5 -10 the next few weeks by an oxpenienced

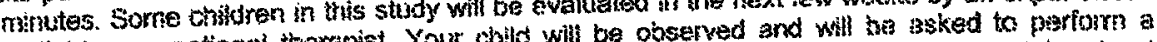
pediatric oxupational therapist. Your child wo home fat your converiensea and will take about serios of play

30 minutes.

Riskes. There are no risics to your child in this study. Results of testirg will bo kept confideritial made avaltable to you if you want. With your written consent, the restits can aise be made avalibis to ary third party you choost.

Tenctits: The potential benefit of you and your chidd's participation in this study is the xnowledge of your chitd's current developmental status. The information chtathad inis study

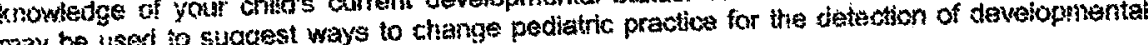
concerns.

Participation in this study is totally voluntary. You can refuse to participate or withdraw from this sivdy at any time withoul aifecting your child's care at the Childran's Cara callitic.

Cosffidentially: Your identity and that of your child will be kept contidential as will the information.

Contact peren: If can call or. Michael Sheveli, at $(5: 4) 412-4363$ or the Medical Director of the Chituren's Carg Cinic. Dr. Nitchell Sitiller, st (514) $696-2442$.

ombutsman: if you have any questions regarding vouriyour child's rights you can cail the

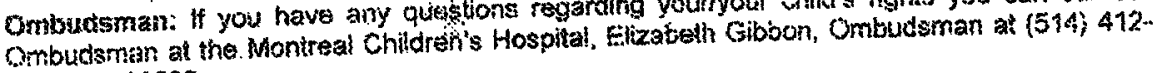
4400 sxt. 22223

Constent I have read and understand the acove. With my signalura jelow I consent tor my child to participate in this study.

Parentigutidian signature

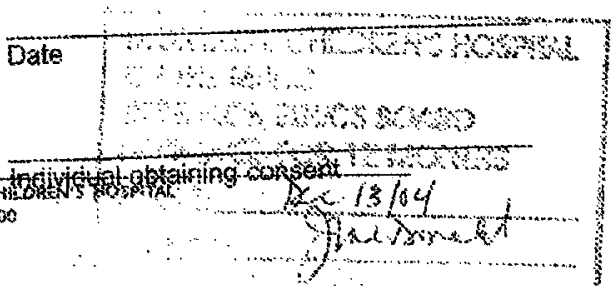

\section{Appendix 4}

\section{Consent Form}


Did you find this questionnaire easy to complete? Place a checkmark in the box that corresponds to your answer.

$\square$ Very easy

$\square$ Fairly easy

$\square$ Neutral

$\square$ Fairly difficult

$\square$ Very difficult

Comment:

\section{Appendix 5}

Likert-style questionnaire collecting data on parent's opinion of the screening instrument. 


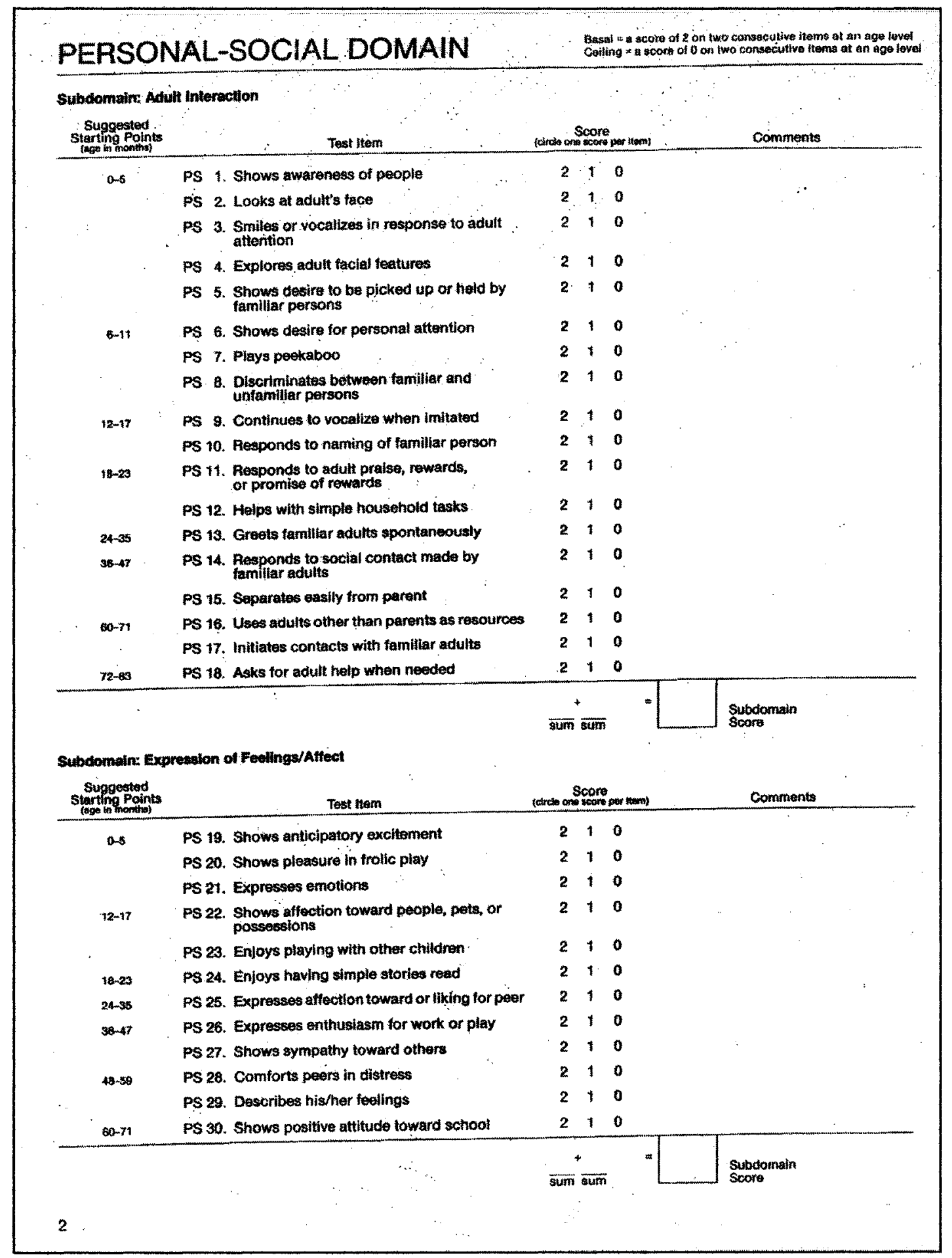

\section{Appendix 7}

Battelle Developmental Inventory (BDI) ${ }^{55}$ marking scheme and items 


\section{Commurucanory}

1. Does your child initate a twowyord sentence? For example, when you say a wo-word phrase, such as "Mama eat," "Daddy play," "Go home," or "What's this?" does your child say both words back to you? (Check "yes" even, it her words are difficult to inderstand.)

2. Does your child say eight words or more in atddition to Mama" arra "Dada"?

3. Without showing him first, does your child point to the correct picture when you say, "Show me the kity" or ask, "Where is the ball?" (He needs to identify only one picture correctly.)

4. Does your child say two or three wonds that represent different fdeas together, such as "See tog," "Mormy come home," or "Kitty gone"? (Don't coumt word combinations that express one ldea, such as "Bye-Bye," "All gone," "All right," and "What's that?")

plezse give an example of your child's word combinations:

5. I you point to a picture of a ball (kitty, cup, hat, etc.) and ask your chllk, "What is this?" does your child correcty name at least one picture?

6. Without giving him clues by pointing or using gestures, can your child carry out at lastat three of these kinds of tirections?
a. "Put the toy on the tabie."
d. "Find your coat."
d. "Take my hand.

b. "Close the door"

c. "Exing me a towel." f. "Gat your book."

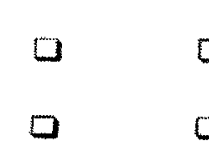

\section{Q}

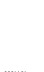

$\square$ 


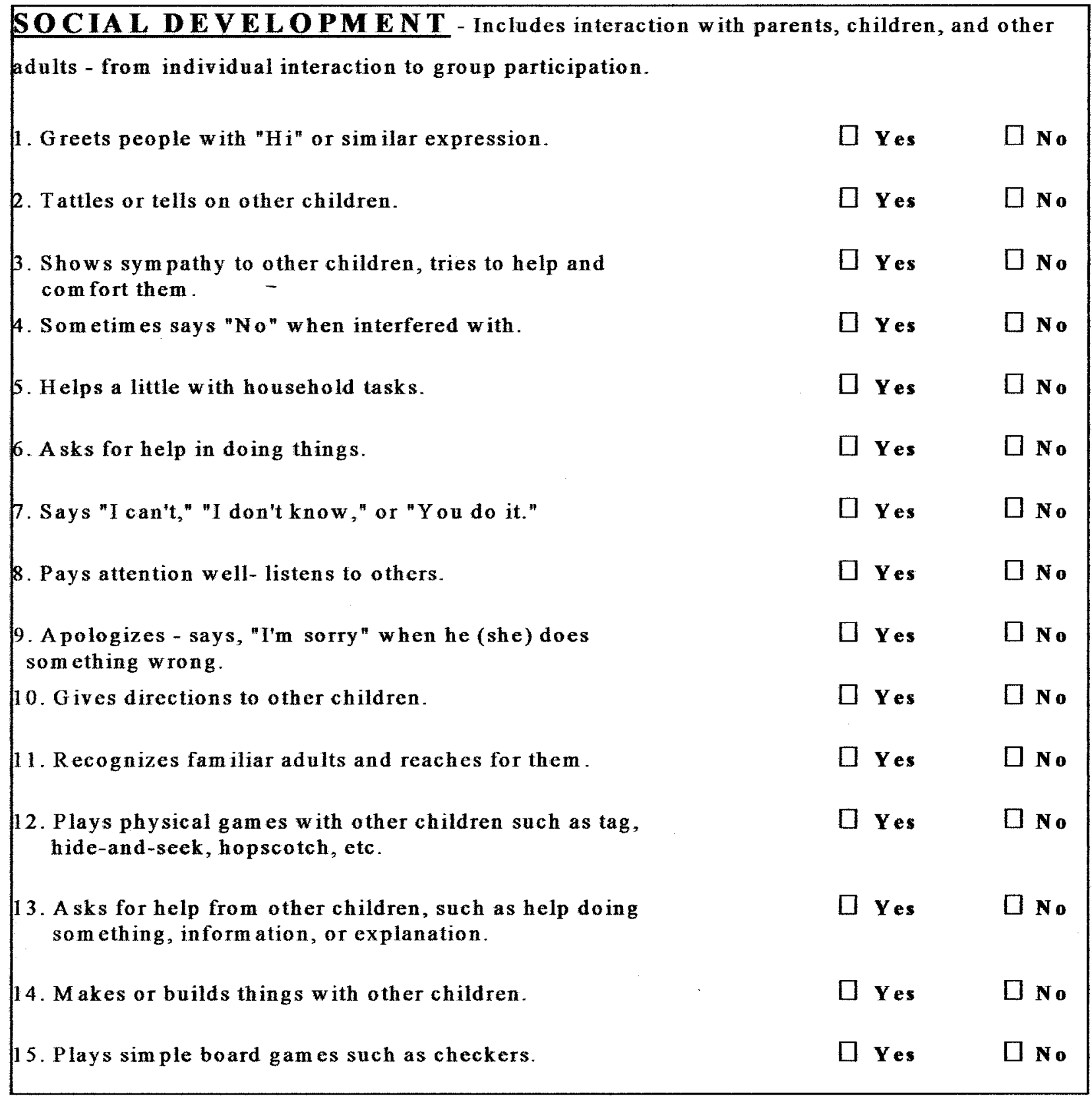

\section{Appendix 9}

First page of the Child Developmental Inventory $(\mathrm{CDI})^{57}$ 